\title{
The Economic Effects of COVID-19 Containment Measures
}

\author{
Pragyan Deb ${ }^{1}$ - Davide Furceri ${ }^{2} \cdot$ Jonathan D. Ostry ${ }^{3} \cdot$ Nour Tawk $^{1}$
}

Accepted: 30 September 2021 / Published online: 14 December 2021

(c) The Author(s), under exclusive licence to Springer Science+Business Media, LLC, part of Springer Nature 2021

\begin{abstract}
This paper examines the economic effects of COVID-19 containment measures using daily global data on containment measures, infections, and economic activity indicators, such as Nitrogen Dioxide $\left(\mathrm{NO}_{2}\right)$ emissions, international and domestic flights, energy consumption, maritime trade, and mobility indices. Results suggest that containment measures had a significant impact on economic activity-equivalent to about a 10 percent loss in industrial production over 30 days following their implementation. Easing of containment measures results in an increase in economic activity, but the effect is lower (in absolute value) to that of tightening. Fiscal measures used to mitigate the crisis were effective in partly offsetting these costs. We also find that school closures and cancellation of public events are among the most effective measures in curbing infections and are associated with low economic costs. Other highly effective measures like workplace closures and international travel restrictions are among the costliest in economic terms.
\end{abstract}

Keywords Covid-19 $\cdot$ Pandemics $\cdot$ Containment measures

JEL E52 $\cdot$ E58 $\cdot$ D43 $\cdot$ L11

Pragyan Deb

pdeb@imf.org

Davide Furceri

dfurceri@imf.org

Jonathan D. Ostry

jostry@imf.org

Nour Tawk

ntawk@imf.org

1 International Monetary Fund, Washington, D.C, USA

2 International Monetary Fund, University of Palermo, Washington, D.C, USA

3 International Monetary Fund and CEPR, Washington, D.C, USA 


\section{Introduction}

Countries worldwide have enacted stringent containment measures and nonpharmaceutical interventions (NPIs) to halt the spread of the coronavirus (COVID-19) pandemic, in a bid to avoid overwhelming the medical system while effective treatments and vaccines are developed. Interventions have ranged from diagnostic testing, contact tracing, isolation and quarantine for infected people, to, importantly, measures aimed at reducing mobility and creating social distancing (containment measures, hereafter).

At the same time, countries have used different strategies when it comes to lockdowns, both in terms of the scale and strictness of enforcement as well as the type of measures used. For example, countries like Italy have resorted to stringent containment measures to curb infections, including restrictions on internal movement, school and workplace closures, public gatherings bans, and stay-athome orders. On the other end of the spectrum, countries like Sweden have kept open schools for younger children, allowed public gatherings for crowds of less than fifty people, and left open restaurants and pubs. From a research standpoint, this heterogeneity in the health responses across countries provides a good natural experiment to assess the economic and health effects of containment measures. Moreover, quantifying these economic effects and whether they vary across types of containment measure is of paramount importance for many policymakers around the world.

Empirical evidence from China and few selected economies (Kraemer et al. 2020; Chinazzi et al. 2020; Tian et al. 2020, Hsiang et al. 2020) as well as for other countries in the world (Deb et al. 2020) suggest that overall, these measures have been effective in flattening the pandemic "curve". In particular, they find that countries that have put in place stringent measures, for example, like in China and Italy, as well as early intervention, such as in New Zealand and Vietnam, may have reduced the number of confirmed cases by more than 90 percent relative to the underlying country-specific path in the absence of interventions.

However, while these measures have contributed to saving lives, therefore providing the foundation for a stronger medium-term growth (see Barro et al. 2020), they are likely to lead to unprecedented short-term economic losses. Indeed, as pointed out by a voluminous, rapidly growing, and mostly theoretical macro-economic literature (Einchebaum et al. 2020, Acemoglu et al. 2020, Alvarez et al. 2020, Atolia et al. 2021), there are significant tradeoffs between flattening the pandemic curve, allowing the health system to cope better with the spread of the virus, and minimizing the short-term economic losses associated with containment measures.

This paper contributes to this literature by providing an empirical assessment of the economic effects of containment measures, using high-frequency indicators. In particular, the paper has three main goals. The first is to quantify the average economic effect-across countries and measures-of containment measures, both in aggregate terms as well as by different types of measures. For this purpose, we assemble daily data on real-time containment measures implemented by 
countries worldwide as well as a unique database containing daily data on several economic activity indicators: Nitrogen Dioxide $\left(\mathrm{NO}_{2}\right)$ emissions-as explained in the next section, our main variable of interest; international and domestic flights; energy consumption; maritime trade; and mobility indices.

Establishing the causal effect on economic activity is difficult. While containment measures have not been introduced to affect economic activity, the decision of implementing them crucially depends on the evolution of the virus, which in turn may affect mobility and economic activity (Maloney and Taskin 2020). This implies that addressing causality requires the researcher to effectively control for this endogenous response which would otherwise bias estimates of the effect of containment measures. The use of daily data allows us to tackle this issue by controlling for the change in the number of infected cases and deaths occurring a day before the implementation of containment measures, as well as for lagged changes in daily economic indicators. We also control for a set of variables which may affect future infections such as daily temperature and humidity levels, other non-pharmaceutical interventions (NPIs) - including enhanced testing, contact tracing and public information campaigns aimed at increasing social awareness, and country-specific time trends. Given lags in the implementation of interventions at daily frequency, this approach effectively controls for the endogenous response of containment measures to the spread of the virus.

Another concern is that containment measures were announced before being implemented and, therefore, were anticipated. This may have resulted in reduced mobility ahead of the implementation of some containment measures and to a bias in the estimates (Fig. 1). We control for changes in mobility to address this concern. Further, as an additional reassurance, we include an analysis of the effect international travel restrictions, which were implemented across countries in response to outbreaks in other countries, before changes in mobility and exogenous to domestic conditions.

Our results suggest that containment measures have had, on average, a very large impact on economic activity-equivalent to a loss of about 10 percent in industrial production over the 30-day period following the implementation of full lockdown. The results also suggest that while the easing of containment measures leads to a rebound in economic activity, this effect is lower (in absolute value) than that from a tightening of containment.

The second goal of the paper is to examine whether announced and implemented fiscal measures, differentiating between demand support and emergency lifelines, have been effective in mitigating the negative effects of containment measures. To answer this question, we use data from the IMF Policy Tracker and the Yale COVID-19 Financial Response Tracker which compile discretionary fiscal measures in response to COVID-19. The results suggest that macroeconomic stimulus has been effective, with the negative effect of containment measures being much larger-equivalent to a loss in industrial production of about 29 percent-in countries that have provided little or limited fiscal policy stimulus. The results also suggest that both demand support and emergency lifeline measures were both effective in mitigating economic losses. 

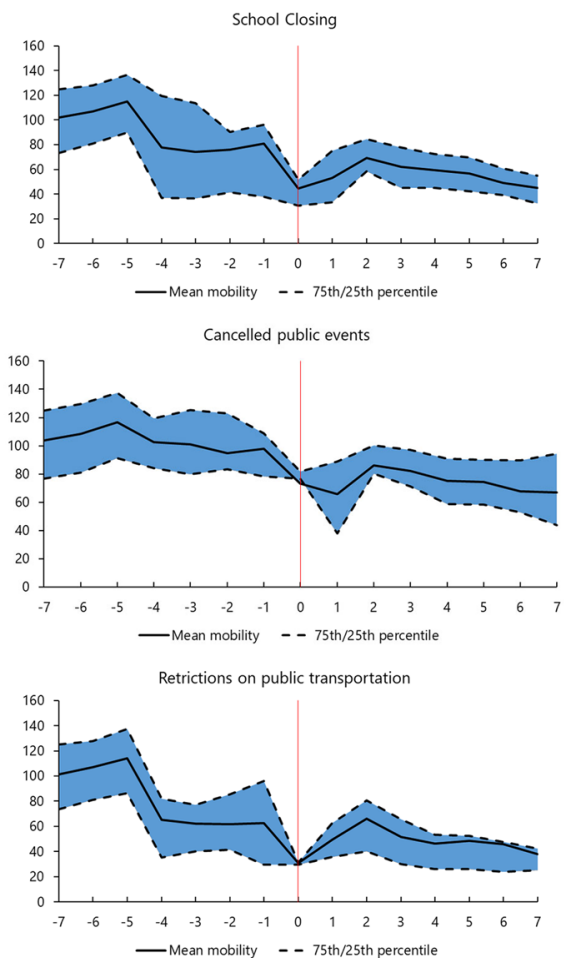

Restrictions on internal movement

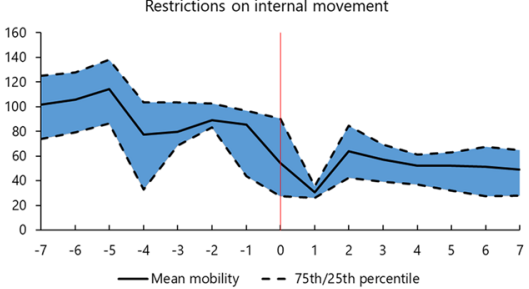

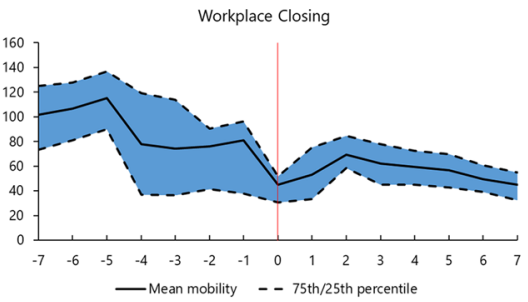
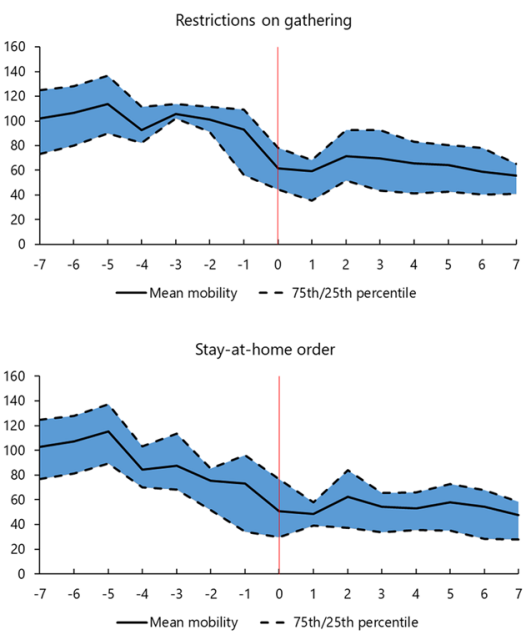

Restriction on international travel

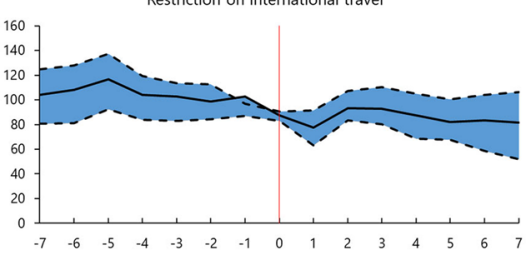

- Mean mobility $\quad--75$ th $/ 25$ th percentile

Sources: Apple Mobility Indices, OxCGRT Stringency Index and IMF Staff calculations. An index $=100$ suggest no decline in mobility compared to trend.

Fig. 1 Mobility before and after containment measures (percent deviation from baseline)

The third and final goal of the paper is to examine which types of containment measures have resulted in larger economic costs and short-term tradeoffs between minimizing health risks and economic losses. For this purpose, we analyze the economic and virus transmission effects of the following containment measures: (i) school closures; (ii) workplace closures; (iii) cancellation of public events; (iv) restrictions on size of gatherings; (v) closures of public transport; (vi) stay-at-home orders; (vii) restrictions on internal movement; (viii) restrictions on international travel. While the results should be treated with caution since many of these measures were often introduced simultaneously as a part of the country's response to limit the spread of the virus, evidence suggests that school closures and cancellations 
of public events are the most effective measures in curbing infections, but also among the least costly in economic terms. On the other hand, while international travel restrictions and workplace closures are also among the most effective in curbing infections and reducing fatalities, they are associated with the largest economic costs.

The paper is structured as follows. Section 2 briefly surveys the literature related to containment measures and the COVID-19 pandemic. Section 3 describes data, stylized facts on $\mathrm{NO}_{2}$ emissions and their association with economic activity, and econometric methodology. Section 4 presents our results on the effect of containment measures, and how these effects vary across countries depending on fiscal measures deployed since the pandemic outbreak, by type of containment measure, and the effects of easing containment. The last section concludes.

\section{Literature Review}

This paper contributes to two main strands of literature. The first is on the economic effects of COVID-19 and containment measures, including based on theoretical and empirical modelling and past pandemic episodes. Einchebaum et al. (2020) extend the classic SIR model by Kermack and McKendrick (1927) to study the equilibrium interactions between economic decisions and the dynamics of epidemics. Their findings suggest that while containment policies and agents' decisions to reduce work and consumption mitigate the severity of the pandemic (measured by total fatalities), this exacerbates the size of the ensuing recession. Acemoglu et al. (2020) study targeted lockdowns in a multi-group SIR model where infections, hospitalizations, and fatality rates can vary between groups based on age demographics. They find that optimal policies targeting different risk and age groups can significantly outperform uniform lockdown policies, with stricter lockdowns on the most vulnerable groups enabling less strict lockdowns (and lower economic losses) for the lower-risk groups. Alvarez et al. (2020) also employ a SIR model to study the optimal lockdown policy for a planner seeking to control fatalities while minimizing the lockdown's output losses. The study finds that an optimal policy requires a stringent lockdown at the beginning of the pandemic, which gradually declines after 3 months. Caulkins et al. (2021) also employ an SIR model to explore optimal lockdown intensities to cope with epidemics and find that different strategies can emerge depending on the policymaker's goals. Aspri et al. (2021) extend the SIR model to an SEAIRD model (where the population is divided among susceptible (S), exposed (E), asymptomatic (A), infected (I), recovered (R), Covid related deceased (D)) with policy controls to study the policymaker's tradeoffs between mortality reduction and GDP losses. They find that for higher thresholds on the statistical value of life, restriction policy (i.e. containment) becomes optimal. Atolia et al. (2021) use a general equilibrium framework with heterogeneous agents to identify the tradeoffs involved in restoring the economy to its pre-Covid-19 state, including the interplay between transmission of the infection, short-term losses and pre-conditions for a longer-term recovery. On past pandemics, Barro et al. (2020) studied the effects of non-pharmaceutical 
interventions (NPIs) such as school closings, prohibition on public gathering and quarantine/isolation on death rates in the United States during the 1919 pandemic. They find that while NPIs have a significant effect on peak death rates, they had a more limited impact on the cumulative number of deaths. They also find that the macroeconomic effects of the pandemic were quite large, with the economy of a typical state contracting by around 6 percent. Ma et al. (2020) draw lessons for the COVID-19 pandemic from examining the immediate and bounce-back effects of six past health crises: the 1968 Flu, SARS (2003), H1N1 (2009), MERS (2012), Ebola (2014), and Zika (2016). They find that real GDP is 2.4 percent lower the year of the outbreak in countries affected relative to those unaffected, and that it remains below its pre-shock levels for five years after the crisis despite bouncing back. They also find that fiscal policy plays an important role in mitigating the impact of a health crisis.

The second strand of the literature this paper contributes to is on the use highfrequency daily indicators to monitor economic activity. For example, Lin and McElroy (2011) show that variation in $\mathrm{NO}_{2}$ emissions in China resemble its GDP growth during and after the GFC. Kumar and Muhuri (2019) employ a transfer learning-based approach to predict per capita GDP of a country using $\mathrm{CO}_{2}$ emissions. Chen et al. (2020) use google mobility indicators to capture the economic impact of the COVID-19 pandemic. Gupta et al. (2020) demonstrate that stay-athome orders led to large increases in unemployment, using data from the US Current Population Survey, and mobility data.

This paper contributes to both strands of the literature by examining empirically the effect of COVID-19 containment measures on economic activity using a wide range of high-frequency indicators and translating these outcomes on lowerfrequency macroeconomic variables. In addition, it empirically assesses the role of fiscal policy in mitigating the adverse effects of the pandemic and explores the differential impact between emergency lifeline and demand support measures in offsetting pandemic losses. Finally, it provides an overview of the costs of different containment measures, as well as their impact on reducing cases and fatalities.

\section{Data, Stylized Facts, $\mathrm{NO}_{2}$ Emissions and Economic Activity, and Methodology}

\subsection{Data}

We assemble a comprehensive daily database of economic indicators-of which $\mathrm{NO}_{2}$ emissions takes central focus - as well as containment measures and COVID19 infections and deaths. Table 4 of the Appendix provides additional details on sources and descriptive statistics. ${ }^{1}$

\footnotetext{
1 A comprehensive description of all the indicators of economic activity is included in the appendix.
} 


\subsubsection{Economic Data}

Nitrogen Dioxide $\left(\mathrm{NO}_{2}\right)$ Emissions We use daily data on Nitrogen Dioxide $\left(\mathrm{NO}_{2}\right)$ emissions from the Air Quality Open Data Platform of the World Air Quality Index (WAQI). Data available on WAQI is collected from countries' respective Environmental Protection Agencies (EPA). The database for $\mathrm{NO}_{2}$ levels covers 62 countries in total, 50 of which are used for our analysis, with coverage beginning from January 1, 2020. The data is based on the median level of emissions reported by city-specific stations which are updated three times a day. Data on $\mathrm{NO}_{2}$ pollution is provided in US EPA standards, which mandates that units of measure for $\mathrm{NO}_{2}$ emissions be parts per billion ( $\mathrm{ppb}$ ). Further, to test the association between the level of $\mathrm{NO}_{2}$ emissions and economic activity, we use OECD data on total man-made emissions of nitrogen oxides for 37 countries, from 1990 to 2018.

\subsubsection{Containment Measures Data}

We use data from the Oxford's COVID-19 Government Response Tracker (OxCGRT) for containment measures. OxCGRT collects information on government policy responses across eight dimensions, namely: (i) school closures; (ii) workplace closures; (iii) public event cancellations; (iv) gathering restrictions; (v) public transportation closures; (vi) stay-at-home orders; (vii) restrictions on internal movement; and (viii) international travel bans. The database scores the stringency of each measure ordinally, for example, depending on whether the measure is a recommendation or a requirement and whether it is targeted or nation-wide. We normalize each measure to range between 0 and 1 to make them comparable. In addition, we compute and aggregate a Stringency Index as the average of the sub-indices, again normalized to range between 0 and 1. The data start on January 1, 2020 and cover 176 countries/regions.

\subsubsection{Fiscal Measures Data}

Data on fiscal stimulus (announced and implemented fiscal packages in percent of 2019 GDP) in response to the COVID-19 pandemic are sourced from the IMF policy tracker. The survey is distributed to country authorities to provide information on policy measures implemented since the beginning of the pandemic, ranging from external, financial, fiscal, monetary, and other policy streams. Responses are collected and updated on a weekly basis. The coverage includes 97 IMF member countries.

To explore the differential impact between types of fiscal measures, demandsupport vs. emergency lifelines, data from the IMF Policy Tracker are complemented with Yale's COVID-19 Financial Response Tracker (CFRT). ${ }^{2}$ Demand-support measures are identified as those which boost demand and households' or firms' disposable

\footnotetext{
2 https://som.yale.edu/faculty-research-centers/centers-initiatives/program-on-financial-stability/covid19-crisis
} 
income, and therefore typically include cash transfers, unemployment insurance, wage subsidies, reduction or deferral of social security or tax payments, paid sick leave, etc. Public investments and healthcare spending measures are considered demand-support measures, given that their role does not entail providing cashflow support. Emergency lifeline measures are identified as those which provide sustained cashflow support to households or firms. Such measures include loans and umbrella guarantees, government provision of loans, equity injections, and other liquidity support measures. The dataset covers fiscal policy measures for 52 countries from January 1 to June 2020, and all data are converted to USD and then scaled to a percent of a country's 2019 GDP.

\subsubsection{COVID-19 Infections and Deaths Data}

Data on infections and deaths are collected from the COVID-19 Dashboard from the Coronavirus Resource Center of Johns Hopkins University. Coverage begins from January 22, 2020. It provides the location and number of confirmed cases, deaths, and recoveries for 211 affected countries and regions.

\subsubsection{Additional Controls Data}

Additional Non-pharmaceutical Interventions We include daily data for the following non-pharmaceutical interventions: testing policies, contacting tracing policies, and public information campaigns. The data are collected from OxCGRT and are available for 176 countries from January 1, 2020.

Temperature and Humidity We include daily data on mean temperature and humidity for 95 countries. The data are collected from the Air Quality Open Data Platform and include humidity and temperature for each major city, based on the median of several stations, in 95 countries from January 1, 2020.

Mobility Trends We collect data on retail and transit-station mobility from Google Mobility Reports. The reports provide daily data by country and highlight the percent change in visits to places related to retail activity (restaurants, cafes, shopping centers, movie theaters, museums, and libraries), or public transport (subways, buses, train stations etc.). The data for each day is reported as the change relative to a baseline value for that corresponding day of the week, and the baseline is calculated as the median value for that corresponding day of the week, during the 5-week period between January 3rd and February 6th, 2020. Daily data are available for over 130 countries, with coverage beginning from February 15, 2020.

\subsection{Stylized Facts}

To curb COVID-19 infections and fatalities, governments worldwide put in place containment measures which have ranged from school closures to restrictions on internal movement and stay-at-home orders. The stringency of such measures 


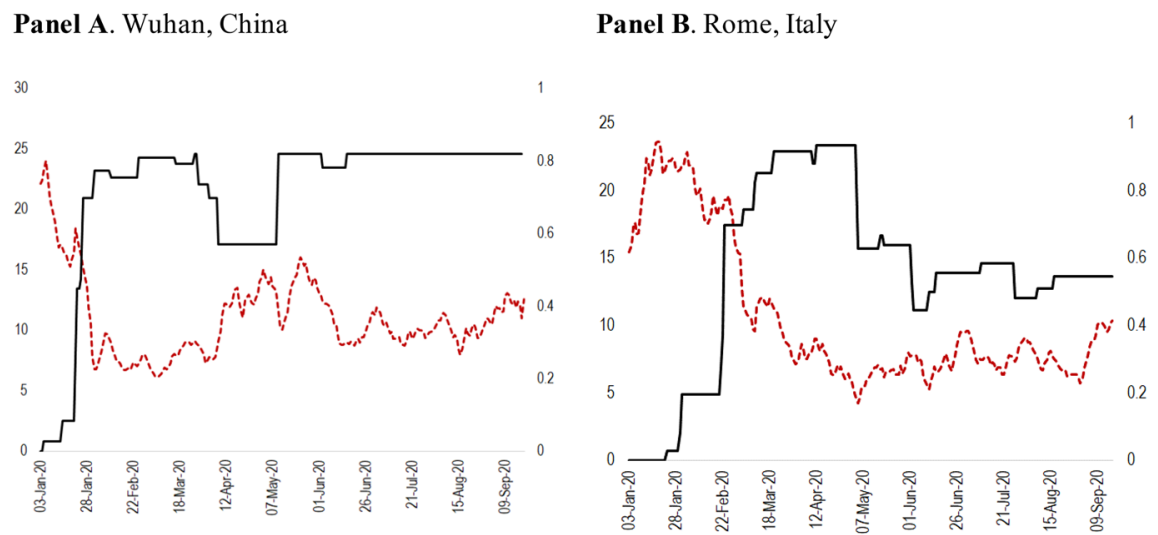

Panel C. New York, USA

Panel D. Stockholm, Sweden
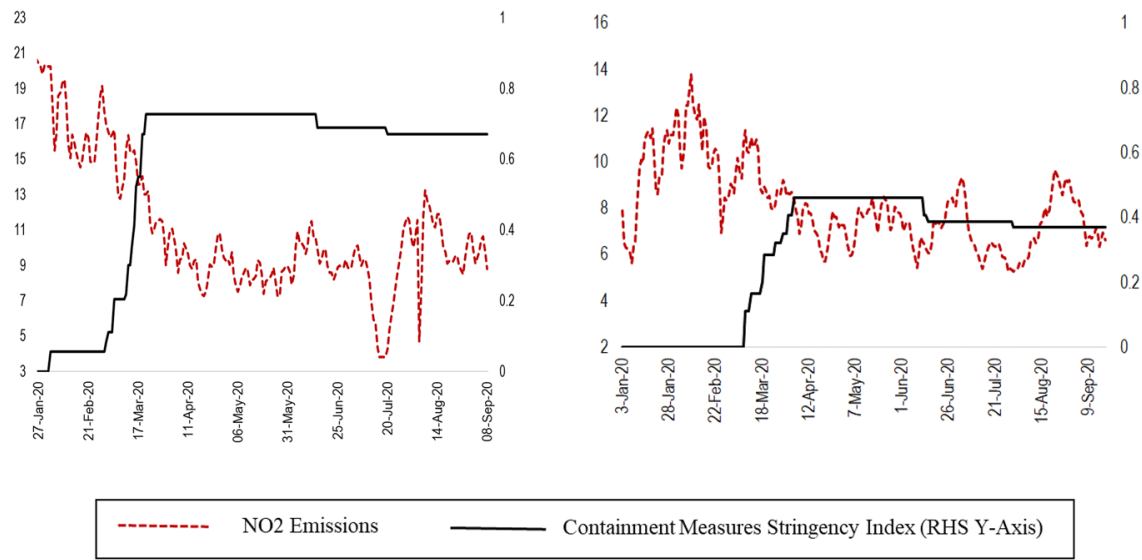

Note: This figure plots $\mathrm{NO}_{2}$ emissions (in parts per billion) and containment measures' stringency indices (in levels) per country, from January 3, 2020 to June 15,2020. Emissions are smoothed with a five-day moving average to remove excess volatility.

Fig. $2 \mathrm{NO}_{2}$ Emissions ( $\left.\mathrm{y}-\mathrm{O}-\mathrm{y}\right)$ and Containment Measures Stringency Indices, Selected Cities

effectively led to shutdowns of production, manufacturing and transportation sectors, and to lockdowns of cities for prolonged periods of time. While initially a supply shock, it morphed into a combined demand and supply shock over time as lockdown measures were kept in place. This section provides a first look at the data to examine whether containment measures have played a role in the observed decline in economic activity, proxied by $\mathrm{NO}_{2}$ emissions. We therefore examine $\mathrm{NO}_{2}$ emissions (year-on-year change) in four cities before and after the implementation of (national) COVID-19 containment measures: Wuhan (China), Rome (Italy), New York (United States), and Stockholm (Sweden).

Figure 2 presents the pattern of $\mathrm{NO}_{2}$ emission (left scale) together with the evolution of the stringency indicator (right scale). It shows that emissions significantly declined in three of these four cities after containment measures were put in place. 
In Wuhan, a dramatic fall in $\mathrm{NO}_{2}$ levels coincided with the enforcement of the cordon sanitaire on January 22, 2020, and the implementation of containment measures in the days that followed. Measures put in place included restrictions on internal movements and gatherings, stay-at-home orders, closures of public transport, and cancellations of public events. By end-March, emissions were back on the rise, as public transport reopened, and restrictions on internal movement and stay-at-home requirements were relaxed (Fig. 2, panel A).

In Rome, the pace of decline in $\mathrm{NO}_{2}$ emissions quickened (Fig. 2, panel B) after containment measures were introduced on February 23, 2020. Measures implemented were restrictive of internal movement, and included school and workplace closures, public gatherings bans, and stay-at-home orders. $\mathrm{NO}_{2}$ levels fell further following the official lockdown of Italy on March 9, and closures of public transport. Since early May, there is a noticeable uptick in $\mathrm{NO}_{2}$ emissions, after four containment measures were relaxed (workplace closures, stay-at-home orders, restrictions on internal movement and international travel), and one was lifted (closures of public transport).

In New York, containment measures were tightened drastically by end-March. Initially, containment measures entailed restrictions on international travel, school closures and cancellations of public events. As the outbreak evolved, restrictions on internal movement and on sizes of gatherings, and closure of workplaces were put in place. Consequently, $\mathrm{NO}_{2}$ emissions fell at a gradual pace and plateaued around their lowest levels after all measures were enforced (Fig. 2, Panel C).

Sweden's response to the COVID-19 pandemic has entailed limited containment measures: restrictions on gatherings; school closures; restrictions on international travel; workplace closures; and restrictions on internal movement. With the exception of international travel restrictions, the other four containment measures implemented rank lowest in stringency: schools for younger children are open, bans on public gatherings are for crowds of over fifty people, and restaurants and pubs remained operational. Consequently, $\mathrm{NO}_{2}$ emissions have not declined significantly in Stockholm (Fig. 2, Panel D). Summarizing, preliminary evidence suggests that containment measures have led to a decline in economic activity, as reflected in lower emissions. The next section checks whether this descriptive evidence holds up to more formal tests.

\subsection{NO2 Emissions and Economic Activity}

Akin to the literature on the use of lights data to predict economic activity (see Henderson et al., 2011, 2012), we establish that $\mathrm{NO}_{2}$ emissions are strongly associated with the level of economic activity. Using data available from the OECD database for total man-made emissions of nitrogen oxides from 1990-2018, we test the sensitivity of such emissions to conventional measures of economic activity such as GDP growth, growth in manufacturing value added and growth in measures of industrial production. Table 1 shows a robust relationship between these economic variables and $\mathrm{NO}_{2}$ emissions. The results, available upon request, suggest an even stronger long-run relation between the level of $\mathrm{NO}_{2}$ emissions and the level of economic activity. 


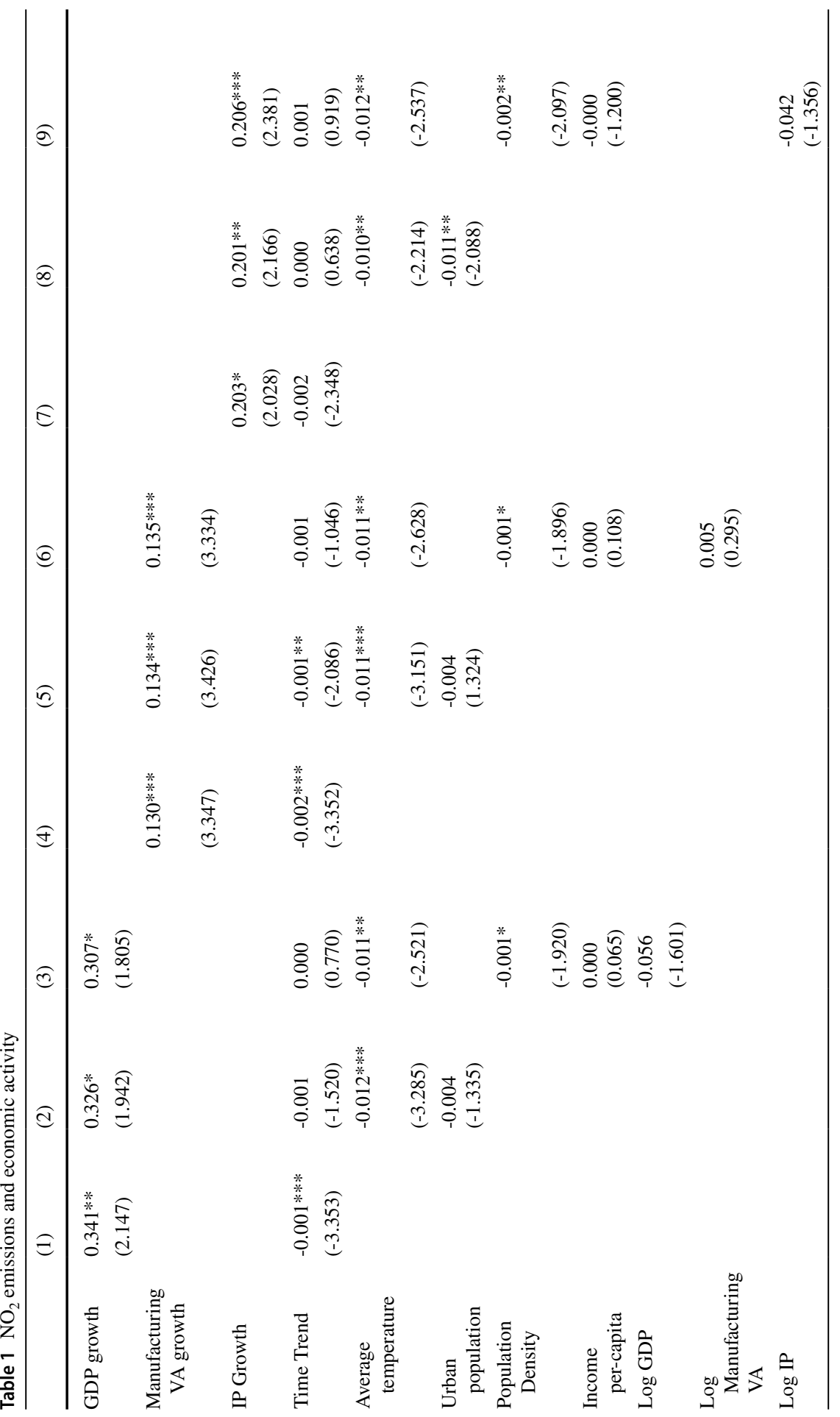




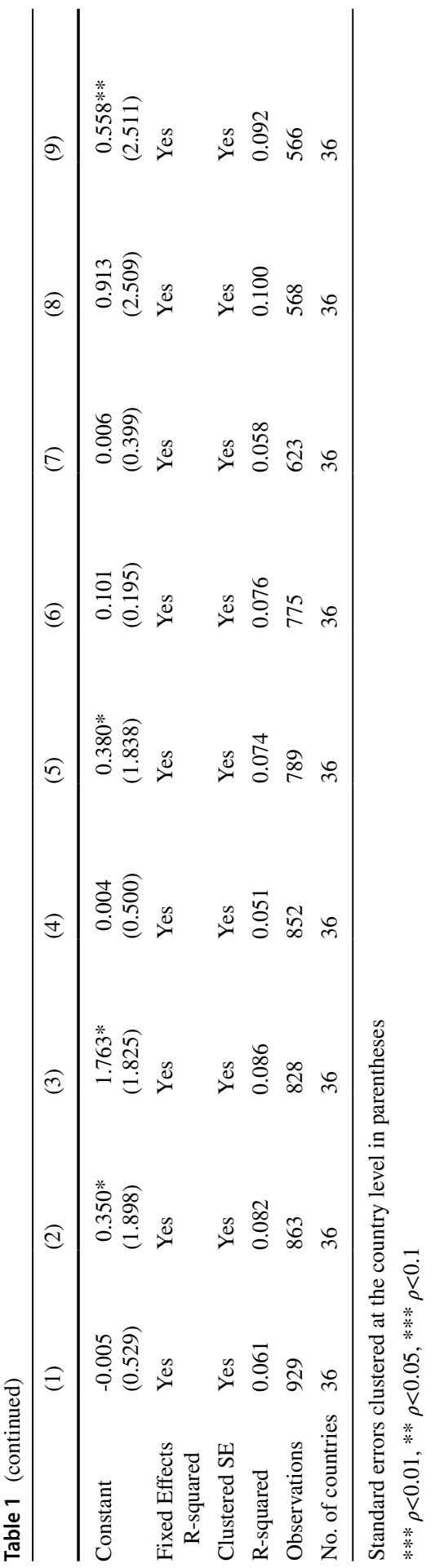


Table $2 \quad \mathrm{NO}_{2}$ emissions and Industrial Production

\begin{tabular}{lll}
\hline & $\begin{array}{l}\text { Industrial Production } \\
\text { (percent) }\end{array}$ & $\begin{array}{l}\text { PMI } \\
\text { (percent) }\end{array}$ \\
\hline Variables & & \\
$\mathrm{NO}_{2}$ emissions (percent) & $\begin{array}{l}0.015^{* *} \\
(0.006)\end{array}$ & $\begin{array}{l}0.03^{* *} \\
(0.016)\end{array}$ \\
Constant & $0.004^{* * *}$ & $-0.014^{* *}$ \\
Observations & $(0.0003)$ & $(0.006)$ \\
R-Squared & 421 & 290 \\
Number of countries & 0.016 & 0.013 \\
\hline
\end{tabular}

The table reports regression results from a regression of industrial production and PMI on monthly $\mathrm{NO}_{2}$ emissions (columns 1 and 2). Standard errors clustered at the country level in parentheses

*** $\rho<0.01 ; * * \rho<0.05 ; * * * \rho<0.1$

To further validate these results, including for the time-period covered in the analysis of the effect of containment measures, we estimate the relationship between $\mathrm{NO}_{2}$ emissions and more traditional measures of economic activity such as industrial production indices and purchase managers index (PMI) using a monthly database of up to 38 countries and monthly levels of $\mathrm{NO}_{2}$ emissions from January 2019 to July 2020 . The results, reported in Table 2, confirm a statistically significant relationship between $\mathrm{NO}_{2}$ emissions and traditional indicators of economic activity at the monthly frequency. ${ }^{3}$

These results help to validate our choice of $\mathrm{NO}_{2}$ emissions as the main variable of interest for the empirical work in this paper. To summarize: (i) emission levels are directly linked to overall economic activity and are not indicative of activity for specific sectors only (as flights would be for tourism, for instance); (ii) data are available on a daily frequency, covering a relatively large sample of 50 countries; and (iii) most important, $\mathrm{NO}_{2}$ emissions are strongly correlated to lower-frequency economic variables which are used in macro-economic analysis, such as GDP growth and industrial production.

\subsection{Methodology}

This section describes the empirical methodology used to examine the causal effect of containment measures on economic activity. Establishing causality is difficult in this context because the decision of countries to implement containment measures crucially depends on the evolution of the virus, which in turn may affect mobility and economic activity (Maloney and Taskin 2020). This implies that addressing causality requires the researcher to effectively control for this endogenous response. Failure to control for possible reverse causality would result in biased estimates of the effect of containment measures.

\footnotetext{
3 In Table 2, we also present the relationship between $\mathrm{NO}_{2}$ and industrial production (PMI) using $\mathrm{NO}_{2}$ as the explanatory variable to directly translate the effect of containment measures on $\mathrm{NO}_{2}$ into the effects on industrial production (PMI).
} 
Table 3 Cumulative effect of containment measure, 30 days after its introduction (log-percentage points)

\begin{tabular}{llll}
\hline & Confirmed cases & $\begin{array}{l}\text { Confirmed } \\
\text { deaths }\end{array}$ & $\mathrm{NO}_{2}$ emissions \\
\hline School Closures & -103 & -28 & -191 \\
Workplace Closures & -81 & -46 & -256 \\
Cancellation of Events & -77 & -27 & -1 \\
International Travel Restrictions & -77 & -48 & -283 \\
Stay-at-Home Requirements & -74 & -32 & -286 \\
Bans on Public Gatherings & -56 & -20 & -128 \\
Restrictions on Internal Movement & -50 & -28 & -174 \\
Closures of Public Transport & -49 & -23 & -328 \\
\hline
\end{tabular}

The results denote the cumulative local projection response to $\mathrm{NO}_{2}$ emissions and confirmed cases to each type of containment measure.' denotes that results are not significant at the 90 percent level 30 days after the introduction of containment measures. Estimates based on $n_{i, t+h}=$ $u_{i}+\sum_{\uparrow=0}^{\mathcal{L}} q_{h, \uparrow} c_{i, t-\uparrow}+X^{\prime}{ }_{i, t} \Gamma_{h}+\sum_{\uparrow=1}^{\mathcal{L}} \psi_{h, \uparrow} \Delta n_{i, t-\uparrow}+\varepsilon_{i, t+h}$ where $n_{i, t}$ is the logarithm of $\mathrm{NO}_{2}$ emissions (or infections) in country $i$ observed at date $t$. The model is estimated at each horizon $h=0,1, \ldots H$, with a lag structure $\uparrow=1,2 \ldots \mathcal{L} ; c_{i, t}$ is the index capturing different types containment measures, introduced one at a time; $X$ is a matrix of time varying control variables and country-specific time trends

We address this issue by controlling for the change in the number of infected cases and deaths the day before implementation of containment measures, as well as for lagged changes in daily economic indicators and in mobility trends. To further account for expectations about the country-specific evolution of the pandemic, we also control for a set of variables which may affect future infections such as daily temperature and humidity levels, other non-pharmaceutical interventions (NPIs) including enhanced testing, contact tracing and public information campaigns aimed at increasing social awareness, and country-specific time trends. Given lags in the implementation of interventions at daily frequency, this allows one to effectively control for the endogenous response of containment measures to the spread of COVID-19.

Another concern is that containment measures were announced before being implemented and, therefore, were anticipated. This may have resulted in reduced mobility ahead of the implementation of some containment measures and to a bias in the estimates. We control for changes in mobility to address this concern. Further, as an additional reassurance, we include an analysis of the effect international travel restrictions, which were implemented across countries in response to outbreaks in other countries, before changes in mobility and exogenous to domestic conditions.

Two econometric specifications are used to estimate the effect of containment measures on economic activity. The first establishes whether containment measures had, on average, significant effects. The second assesses whether these effects vary across countries depending on country-specific policy responses, such as the magnitude of the fiscal support.

We follow the approach proposed by Jordà (2005) to assess the dynamic cumulative effect of containment measures on economic activity, a methodology used also by Auerbach and Gorodnichenko (2013), Ramey and Zubairy (2018), and Alesina 
et al. (2019) among others. This procedure does not impose the dynamic restrictions embedded in vector autoregressions and is particularly suited to estimating nonlinearities in the dynamic response. ${ }^{4}$ The first regression we estimate is:

$$
n_{i, t+h}=u_{i}+\sum_{\uparrow=0}^{\mathcal{L}} q_{h, \uparrow} c_{i, t-\uparrow}+X_{i, t}^{\prime} \Gamma_{h}+\sum_{\uparrow=1}^{\mathcal{L}} \psi_{h, \uparrow} \Delta n_{i, t-\uparrow}+\varepsilon_{i, t+h}
$$

where $n_{i, t+h}$ represents the logarithm of the daily economic indicator (the level of $\mathrm{NO}_{2}$ emissions) in country $i$ observed at date $t ; c_{i, t}$ is the OxCGRT Stringency Index $\left(c_{i, t}\right)$; $u_{i}$ are country-fixed effects to account for time-invariant country-specific characteristics; $X$ is a vector of control variables which includes lags of the containment measures, the amount of number of COVID-19 infections and deaths in country $i$ observed at date $t$, lagged changes in mobility, and a set of variable which may affect future infections such as daily temperature and humidity levels, other non-pharmaceutical interventions (NPIs) - including enhanced testing, contact tracing and public information campaigns aimed at increasing social awareness, and country-specific time trends. ${ }^{5}$

The second specification allows the response to vary with the degree of fiscal stimulus. It is estimated as follows:

$$
\begin{gathered}
n_{i, t+h}=u_{i}+\theta_{h}^{L} F\left(z_{i, t}\right) c_{i, t}+\theta_{h}^{H}\left(1-F\left(z_{i, t}\right)\right) c_{i, t}+X^{\prime}{ }_{i, t} F\left(z_{i, t}\right) \Gamma_{h}{ }^{L}+X^{\prime}{ }_{i, t}\left(1-F\left(z_{i, t}\right) \Gamma_{h}{ }^{H}\right. \\
+\sum_{\uparrow=1}^{\mathcal{L}} F\left(z_{i, t}\right) \psi_{h, \uparrow} \Delta n_{i, t-\uparrow}+\sum_{\uparrow=1}^{\mathcal{L}}\left(1-F\left(z_{i, t}\right)\right) \psi_{h, \uparrow} \Delta n_{i, t-\uparrow}+\varepsilon_{i, t+h} \\
\text { with } F\left(z_{i t}\right)=\exp ^{-\gamma z_{i t}} /\left(1-\exp ^{-\gamma z_{i t}}\right), \gamma>0
\end{gathered}
$$

where $z$ is the fiscal stimulus (as percent of GDP) normalized to have zero mean and a unit variance.

The weights assigned to each regime vary between 0 and 1 according to the weighting function $F\left(\right.$.), so that $F\left(z_{i t}\right)$ can be interpreted as the probability of being in a given regime. The coefficients $\theta_{h}^{L}$ and $\theta_{h}^{H}$ capture the impact of containment measures at each horizon $h$ in cases of very low fiscal stimulus $\left(F\left(z_{i t}\right) \approx 1\right.$ when $z$ goes to minus infinity) and very high fiscal stimulus $\left(1-F\left(z_{i t}\right) \approx 1\right.$ when $\mathrm{z}$ goes to plus infinity), respectively. $F\left(z_{i t}\right)=0.5$ corresponds to average fiscal stimulus.

This approach is equivalent to the smooth transition autoregressive model developed by Granger and Terävistra (1993). The advantage of this approach is twofold. First, compared with a model with linear interaction terms - that is, a model, that assumes that the effect of containment depends linearly on fiscal stimulus, it permits a direct test of whether the effect of containment measures varies across different country-specific "regimes". Second, compared with estimating structural vector

\footnotetext{
${ }^{4}$ See Deb et al. (2020) and Jinjarak et al. (2020), among others, for a similar approach to study the effect of containment on cases and deaths.

5 Since emissions are affected by climatic conditions, we include temperature and humidity levels as controls - the results, however, are almost identical excluding these variables. Data are collected from the Air Quality Open Data Platform and include humidity and temperature for each major city, from January 1, 2020.
} 

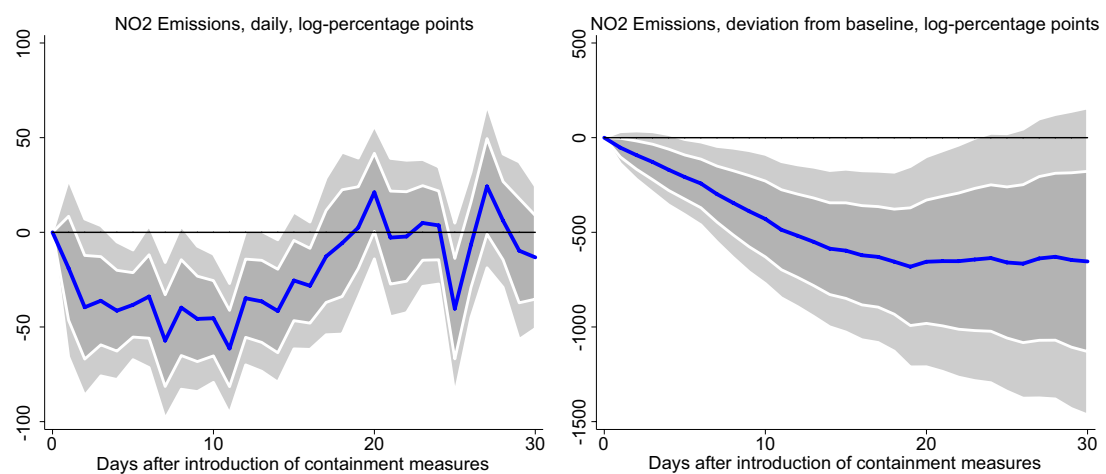

Note. Impulse response functions are estimated for a sample of 50 countries using daily data from January 1,2020. The graph shows the response and confidence bands at 90 and 95 percent. The horizontal axis shows the response $\mathrm{x}$ days after the containment measures. Estimates based on $n_{i, t+h}=u_{i}+\sum_{\ell=0}^{\mathcal{L}} \mathrm{q}_{h, \ell} c_{i, t-\ell}+X_{i, t}^{\prime} \Gamma_{h}+\sum_{\ell=1}^{\mathcal{L}} \psi_{h, \ell} \Delta n_{i, t-\ell}+\varepsilon_{i, t+h}$ where $n_{i, t}$ is the logarithm of $\mathrm{NO}_{2}$ emissions in country $i$ observed at date $t$. The model is estimated at each horizon $h=0,1, \ldots H$, with a lag structure $\ell=1,2 \ldots \mathcal{L} ; c_{i, t}$ is the index capturing the level of containment measures; $X$ is a matrix of time varying control variables and country specific time trends. The regression is estimated using both daily $\mathrm{NO} 2 \mathrm{emissions}$ (left panel) and cumulative emissions (right panel) over period 1 to $h$ to obtain relevant coefficients and standard errors.

Fig. 3 Effect of Containment Measures on Total Nitrogen Dioxide $\left(\mathrm{NO}_{2}\right)$ Emissions

autoregressions for each regime, it allows the effect of containment to vary smoothly across regimes by considering a continuum of states to compute impulse responses, thus making the functions more stable and precise.

Equations (1) and (2) are estimated for each day $h=0, . ., 30$. Impulse response functions are computed using the estimated coefficients $\theta_{h}$, and the 90 and 95 percent confidence bands associated with the estimated impulse-response functions are obtained using the estimated standard errors of the coefficients $\theta_{h}$, based on robust standard errors clustered at the country level. Our sample consists of a balanced sample of 50 economies. The data cut-off date is September $18,2020$.

\section{Results}

\subsection{Impact of Containment on $\mathrm{NO}_{2}$ Emissions}

Figure 3 shows the estimated dynamic response of $\mathrm{NO}_{2}$ emissions to a unitary change in the aggregate containment stringency index over the 30-day period following the implementation of containment measures, together with the 90 and 95 percent confidence interval around the point estimates. The left-hand panel shows the responses of daily change of $\mathrm{NO}_{2}$ emissions while the right-hand panel shows the cumulative response (which can be thought of as a proxy for lost output). ${ }^{6}$

\footnotetext{
${ }^{6}$ Cumulative impulse responses are computed using cumulative changes in $\mathrm{NO} 2$ as the dependent variable.
} 
(a): With Time-Fixed Effects

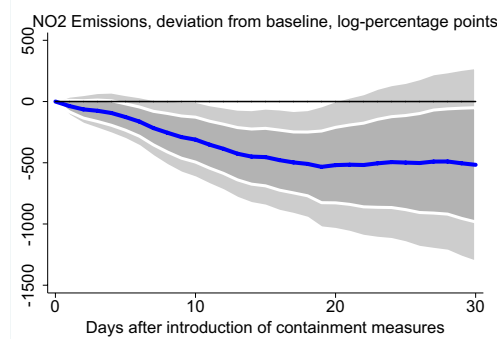

(c): With leads of Stringency Index

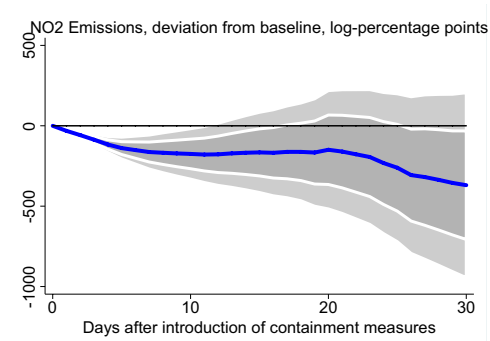

(b): With data restricted to lockdown periods only

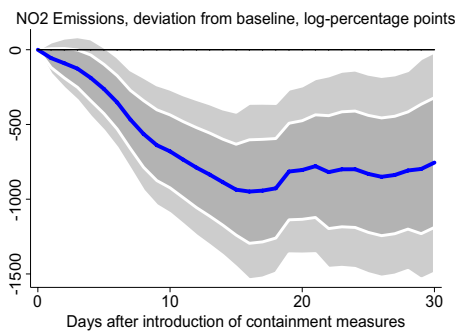

(d): With Contemporaneous $\mathrm{NO}_{2}$ emissions

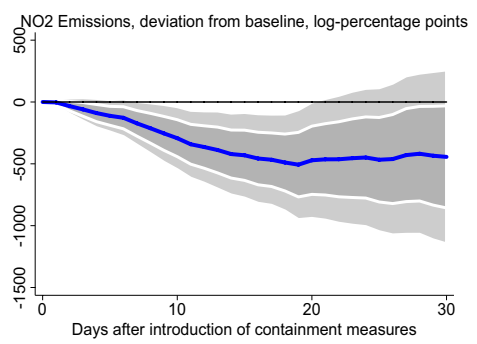

Note: Impulse response functions are estimated using a sample of 50 countries using daily data from the start of the outbreak. The graph shows the response and confidence bands at 90 and 95 percent. The horizontal axis shows the response $\mathrm{x}$ days after the containment measures. Estimates based on $n_{i, t+h}=u_{i}+\sum_{\ell=0}^{\mathcal{L}} \mathrm{q}_{h, \ell} c_{i, t-\ell}+X_{i, t}^{\prime} \Gamma_{h}+\sum_{\ell=1}^{\mathcal{L}} \psi_{h, \ell} \Delta n_{i, t-\ell}+\varepsilon_{i, t+h}$ where $n_{i, t}$ is the logarithm of $\mathrm{NO}_{2}$ emissions in country $i$ observed at date $t$. The model is estimated at each horizon $h=0,1, \ldots H$, with a lag structure $\ell=1,2 \ldots \mathcal{L} ; c_{i, t}$ the index capturing the level of containment and mitigation measures; $X$ is a matrix of time varying control variables and country specific time trends.

Fig. 4 Robustness checks

The results provide evidence that containment measures have significantly reduced the amount of $\mathrm{NO}_{2}$ emissions: in countries where stringent containment measures were implemented, these may have reduced the amount of $\mathrm{NO}_{2}$ emissions cumulatively by almost 99 percent 30 days after their implementation, relative to the underlying country-specific path in the absence of intervention. ${ }^{7}$ Translating the estimated effect on $\mathrm{NO}_{2}$ emissions from the results in Table 2, this implies that containment measures may have led to an approximate decline of 10 percent (monthon-month) in industrial production, and of -20 percent (month-on-month) in manufacturing PMI.

We conducted several robustness checks of our main finding. First, we included daily time fixed effects as additional controls. Second, we restrict the data to end on June 1, 2020 so as to exclude data which may capture the relaxing of containment measures and so are able to focus on the lockdown phase of the pandemic exclusively, given that containment measures began to be eased in most countries beyond June. Third, we follow Teulings and Zubanov (2014) and include leads of

\footnotetext{
${ }^{7}$ As for $\mathrm{NO}_{2}$, the percent effects are computed as $\left(\mathrm{e}^{\mathrm{q}_{h}-1}\right)^{*} 100$. We also find that energy consumption as well as flights are positively correlated with industrial production growth-both correlations are statistically significant at 5 percent.
} 
Full sample - January 1, 2020 to August 20, 2021
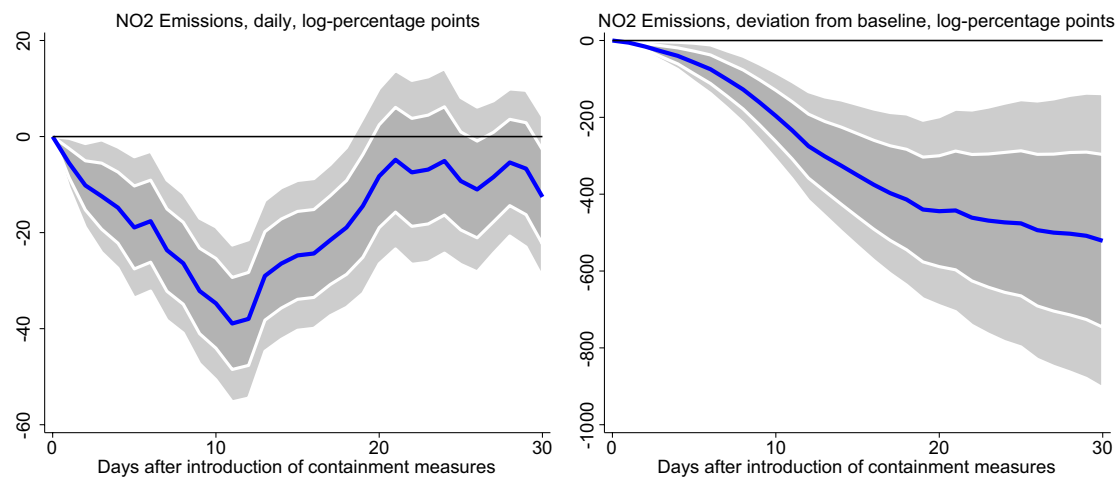

Recent sample - September 19, 2020 to August 20, 2021
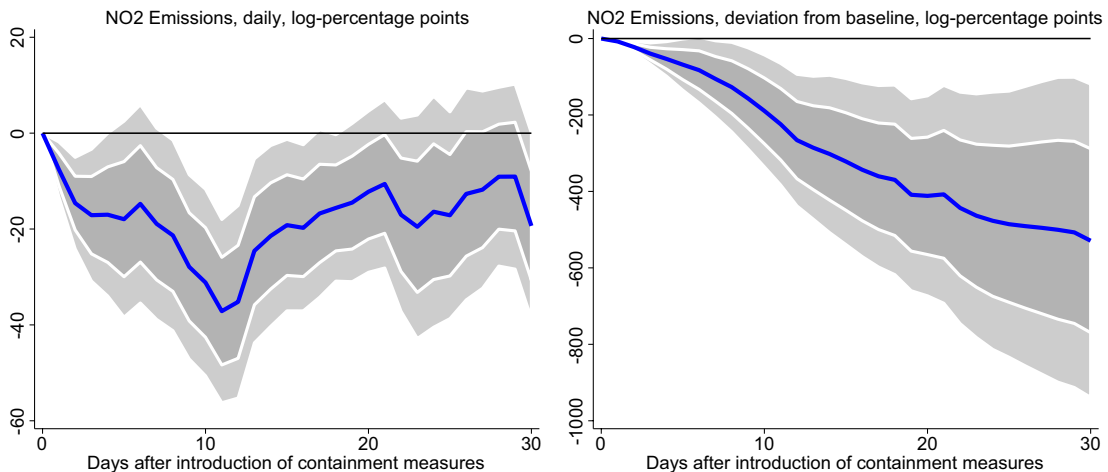

Note: Impulse response functions are estimated using a sample of 50 countries using daily data. The graph shows the response and confidence bands at 90 and 95 percent. The horizontal axis shows the response $\mathrm{x}$ days after the containment measures. Estimates based on $n_{i, t+h}=u_{i}+\sum_{\ell=0}^{\mathcal{L}} \mathrm{q}_{h, \ell} c_{i, t-\ell}+X_{i, t}^{\prime} \Gamma_{h}+\sum_{\ell=1}^{\mathcal{L}} \psi_{h, \ell} \Delta n_{i, t-\ell}+\varepsilon_{i, t+h}$ where $n_{i, t}$ is the logarithm of $\mathrm{NO}_{2}$ emissions in country $i$ observed at date $t$. The model is estimated at each horizon $h=0,1, \ldots H$, with a lag structure $\ell=1,2 \ldots \mathcal{L} ; c_{i, t}$ the index capturing the level of containment and mitigation measures; $X$ is a matrix of time varying control variables and country specific time trends. The regression is estimated using both daily NO2 emissions (left panel) and cumulative emissions (right panel) over period 1 to $h$ to obtain relevant coefficients and standard errors.

Fig. 5 Robustness check - extended sample

the stringency index $-\sum_{k=1}^{h}\left(\varphi_{k} R_{j, t+k}\right)$, which control for containment measures introduced within the response horizon $t+h$ (for $h>1$ ). Fourth, to further mitigate reverse causality, we use the contemporaneous change in $\mathrm{NO}_{2}$ emissions as a control and estimate the impact only after one day of the implementation of containment measures. In all cases, the results are very similar to, and not statistically different from, the baseline (Fig. 4). Finally, another concern is related to the potential seasonality of $\mathrm{NO}_{2}$ emissions. In particular, it could be the case that the level of emissions tends to systematically decline during the first months of the year-the main sample of our analysis. To check for this possibility, we re-estimate the relationship between $\mathrm{NO}_{2}$ emissions and monthly fixed effects using Eq. (2), relying on 

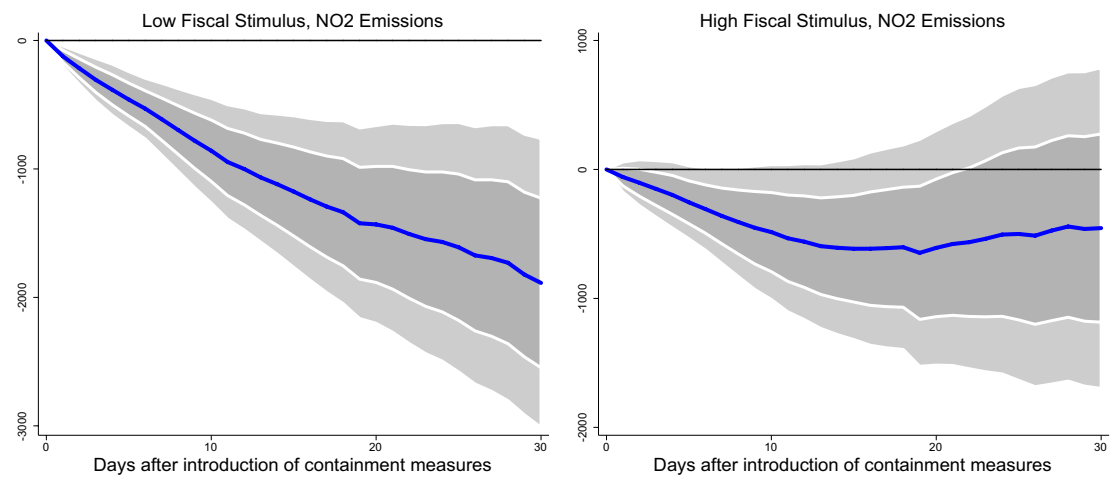

Note. Impulse response functions are estimated using a sample of 50 countries using daily data from the start of the outbreak. The graph shows the response and confidence bands at 90 and 95 percent. The horizontal axis shows the response $\mathrm{x}$ days after the containment measures. Estimates based on $n_{i, t+h}=u_{i}+u_{t}+\theta_{h}^{L} F\left(z_{i, t}\right) c_{i, t}+\theta_{h}^{H}\left(1-F\left(z_{i, t}\right)\right) c_{i, t}+X_{i, t}^{\prime} \Gamma_{h}+\sum_{\ell=1}^{f} F\left(z_{i, t}\right) \psi_{h, \ell} \Delta n_{i, t-\ell}+\sum_{\ell=1}^{\ell}\left(1-F\left(z_{i, t}\right)\right) \psi_{h, \ell} \Delta n_{i, t-\ell}+$ $\sum_{\ell=1}^{\ell} \mathrm{q}_{h, \ell} c_{i, t-\ell}+\varepsilon_{i, t+h}$ with $F\left(z_{i t}\right)=\frac{\exp \gamma z_{i t}}{\left(1-e x p-\gamma z_{i t}\right)}, \gamma>0$ where $n_{i, t}$ is the logarithm of $\mathrm{NO}_{2}$ emissions in country $i$ observed at date $t$ and $z$ is the fiscal stimulus normalized to have zero mean and a unit variance. The model is estimated at each horizon $h=0,1, \ldots H$, with a lag structure $\ell=$ $1,2 \ldots \mathcal{L} ; c_{i, t}$ is the index capturing the level of containment and mitigation measures; $X$ is a matrix of time varying control variables and country specific time trends. The regression is estimated using both daily NO2 emissions (left panel) and cumulative emissions (right panel) over period 1 to $h$ to obtain relevant coefficients and standard errors. low fiscal stimulus denote when $\mathrm{F}(\mathrm{z}) \approx 1$ when and high fiscal stimulus when $\left(1-\mathrm{F}\left(\mathrm{z}_{-}\right.\right.$it $\left.) \approx 1\right)$.

Fig. 6 Effect of Containment Measures on $\mathrm{NO}_{2}$ Emissions, Interaction with Overall Fiscal Measures

the monthly database of 38 countries from January 2019 to April 2020. The results, not reported, show that, with the exception of October, monthly fixed effects are typically not statistically significant, suggesting that seasonality is not an important empirical issue in our analysis.

Finally, while the focus of this paper is on the first wave of the COVID-19 pandemic and the associated containment measures - as arguably, during the first pandemic wave the choice of introducing containment measures (and their stringency) was almost exclusively based on health factors and therefore more exogenous to economic activity - we extended the analysis to include data from beyond September 18, 2020 to latest available (August 20,2021) and the results remain robust. Figure 5, top panel presents our baseline results for the entire sample spanning January 1, 2020 to August 20, 2021, while Fig. 5, bottom panel focuses on the new period (after the first wave of the pandemic in most countries).

\subsection{Role of Fiscal Policy}

Governments around the world announced and implemented unprecedented economic measures in response to the COVID-19 pandemic. As of September 18, 2020, more than 90 countries worldwide had deployed (or announced) fiscal measures to mitigate the impact of the pandemic. Fiscal packages were heterogeneous in size, ranging from less than 1 percent of GDP, to as much 12 percent of GDP for Japan and Luxembourg. This section examines whether such measures have been effective 


\title{
A. Demand Support Measures
}
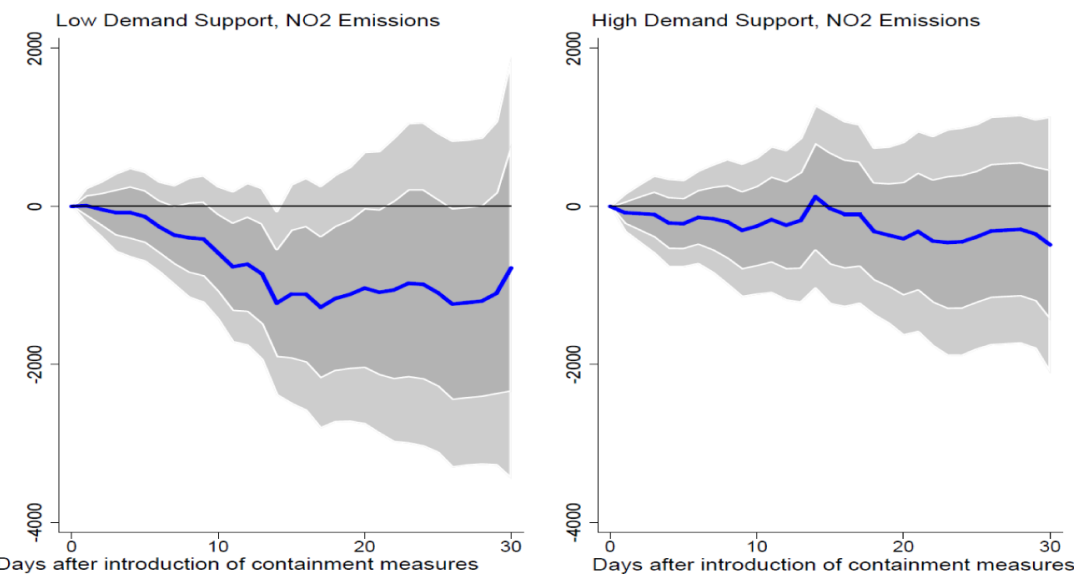

\section{B. Emergency Lifelines}
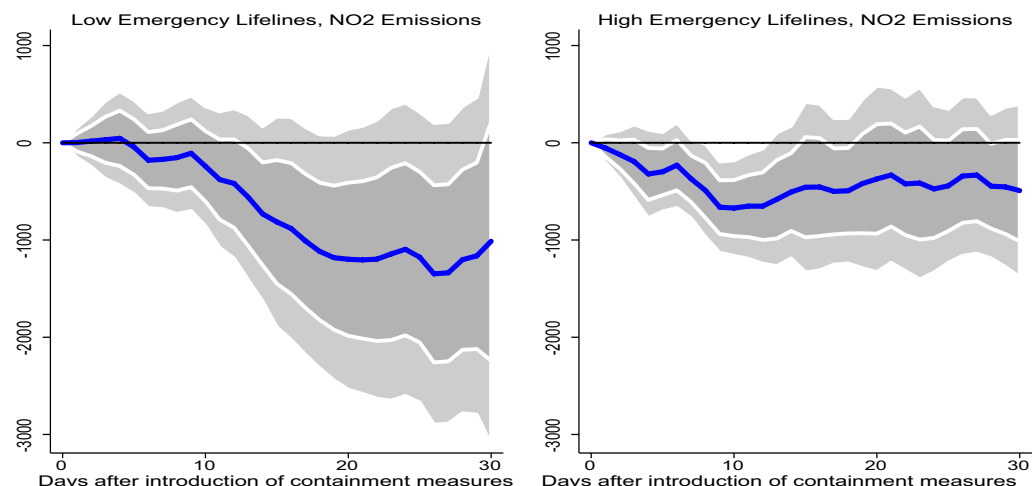

\begin{abstract}
Note. Impulse response functions are estimated using a sample of 50 countries using daily data from the start of the outbreak. The graph shows the response and confidence bands at 90 and 95 percent. The horizontal axis shows the response $\mathrm{x}$ days after the containment measures. Estimates based on $n_{i, t+h}=u_{i}+u_{t}+\theta_{h}^{L} F\left(z_{i, t}\right) c_{i, t}+\theta_{h}^{H}\left(1-F\left(z_{i, t}\right)\right) c_{i, t}+X_{i, t}^{\prime} \Gamma_{h}+\sum_{\ell=1}^{L} F\left(z_{i, t}\right) \psi_{h, \ell} \Delta n_{i, t-\ell}+\sum_{\ell=1}^{L}\left(1-F\left(z_{i, t}\right)\right) \psi_{h, \ell} \Delta n_{i, t-\ell}+$

$\sum_{\ell=1}^{\mathcal{L}} \mathrm{q}_{h, \ell} c_{i, t-\ell}+\varepsilon_{i, t+h}$ with $F\left(z_{i t}\right)=\frac{\exp ^{-\gamma z_{i t}}}{\left(1-\exp ^{\left.-\gamma z_{i t}\right)}\right.}, \gamma>0$ where $n_{i, t}$ is the logarithm of $\mathrm{NO}_{2}$ emissions in country $i$ observed at date $t$ and $z$ is the fiscal stimulus normalized to have zero mean and a unit variance. The model is estimated at each horizon $h=0,1, \ldots H$, with a lag structure $\ell=$ $1,2 \ldots \mathcal{L} ; c_{i, t}$ is the index capturing the level of containment and mitigation measures; $X$ is a matrix of time varying control variables and country specific time trends. The regression is estimated using both daily NO2 emissions (left panel) and cumulative emissions (right panel) over period 1 to $h$ to obtain relevant coefficients and standard errors. low fiscal stimulus denote when $\mathrm{F}(\mathrm{z}) \approx 1$ when and high fiscal stimulus when $\left(1-\mathrm{F}\left(\mathrm{z}_{-}\right.\right.$it $\left.) \approx 1\right)$.
\end{abstract}

Fig. 7 Effect of Containment Measures on $\mathrm{NO}_{2}$ Emissions, Interaction with Types of Fiscal Measures

in mitigating the negative effects of containment measures, using data on discretionary fiscal measures implemented in response to COVID-19 provided by the IMF Policy Tracker. We explore whether the average effect of containment measures varies depending on the magnitude of policy responses deployed.

To examine the role of fiscal stimulus in mitigating the decline in $\mathrm{NO}_{2}$ emissions, we estimate Eq. (2) with an interaction term which measures the amount of fiscal 

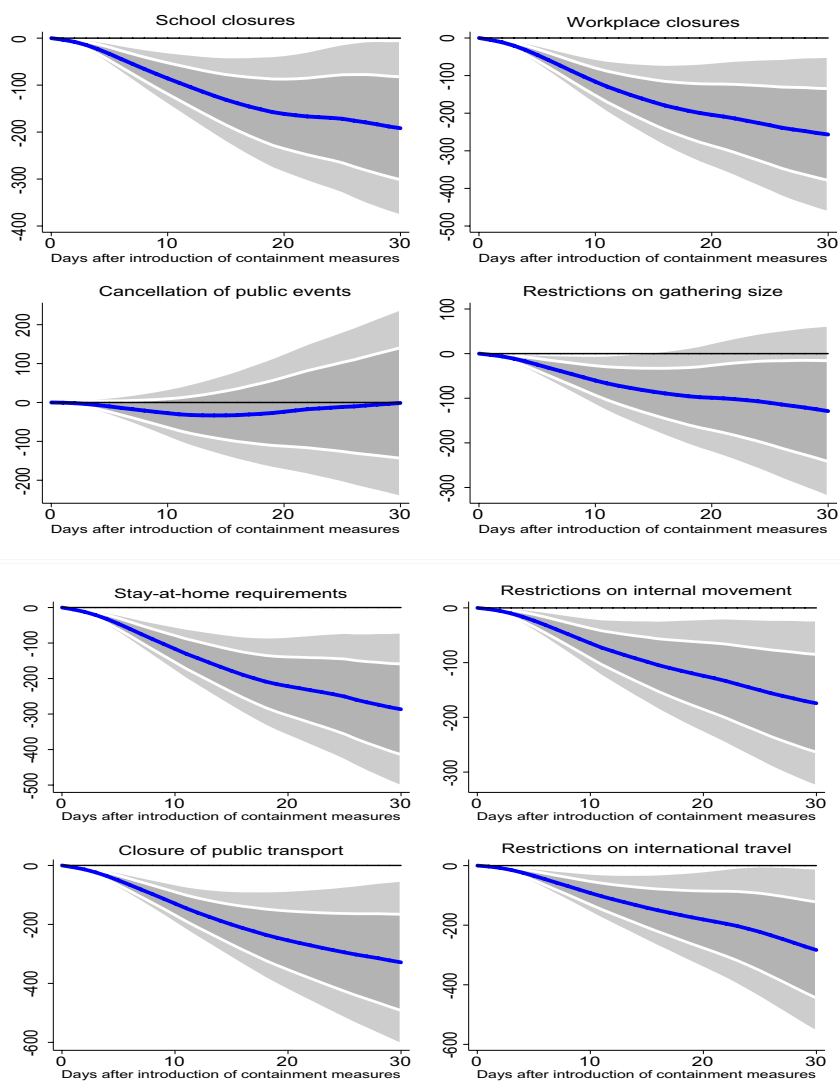

Note: Impulse response functions are estimated using a sample of 50 countries using daily data from the start of the outbreak. The graph shows the response and confidence bands at 90 and 95 percent. The horizontal axis shows the response $\mathrm{x}$ days after the containment measures. Estimates based on $n_{i, t+h}=u_{i}+\mathrm{q}_{h} c_{i, t}+X_{i, t}^{\prime} \Gamma_{h}+\sum_{\ell=1}^{\mathcal{L}} \psi_{h, \ell} \Delta n_{i, t-\ell}+\varepsilon_{i, t+h}$ where $n_{i, t}$ is the logarithm of $\mathrm{NO}_{2}$ emissions in country $i$ observed at date $t$. The model is estimated at each horizon $h=0,1, \ldots H$, with a lag structure $\ell=$ $1,2 \ldots \mathcal{L} ; c_{i, t}$ is the index capturing different types containment and mitigation measures, introduced one at a time; $X$ is a matrix of time varying control variables and country time trends.

Fig. 8 Local projection response of $\mathrm{NO}_{2}$ emissions to types of containment measures (one by one)

stimulus (as a percent of 2019 GDP) deployed since the beginning of the pandemic. The results in Fig. 5 show that containment measures have had a larger adverse impact on economic activity in economies with relatively small fiscal packagesequivalent to a 29 percent decline in industrial production. In contrast, the impact is much lower ( 7 percent) and not statistically different from zero in countries that deployed large fiscal stimulus packages. ${ }^{8}$ Consistent with the evidence of Ma et al. (2020) on previous pandemics, this suggests that fiscal stimulus measures can play a crucial role during the COVID-19 pandemic to mitigate the economic fallout of the crisis.

\footnotetext{
${ }^{8}$ The impulse responses under the two regimes are statistically different from each other at 5 percent.
} 

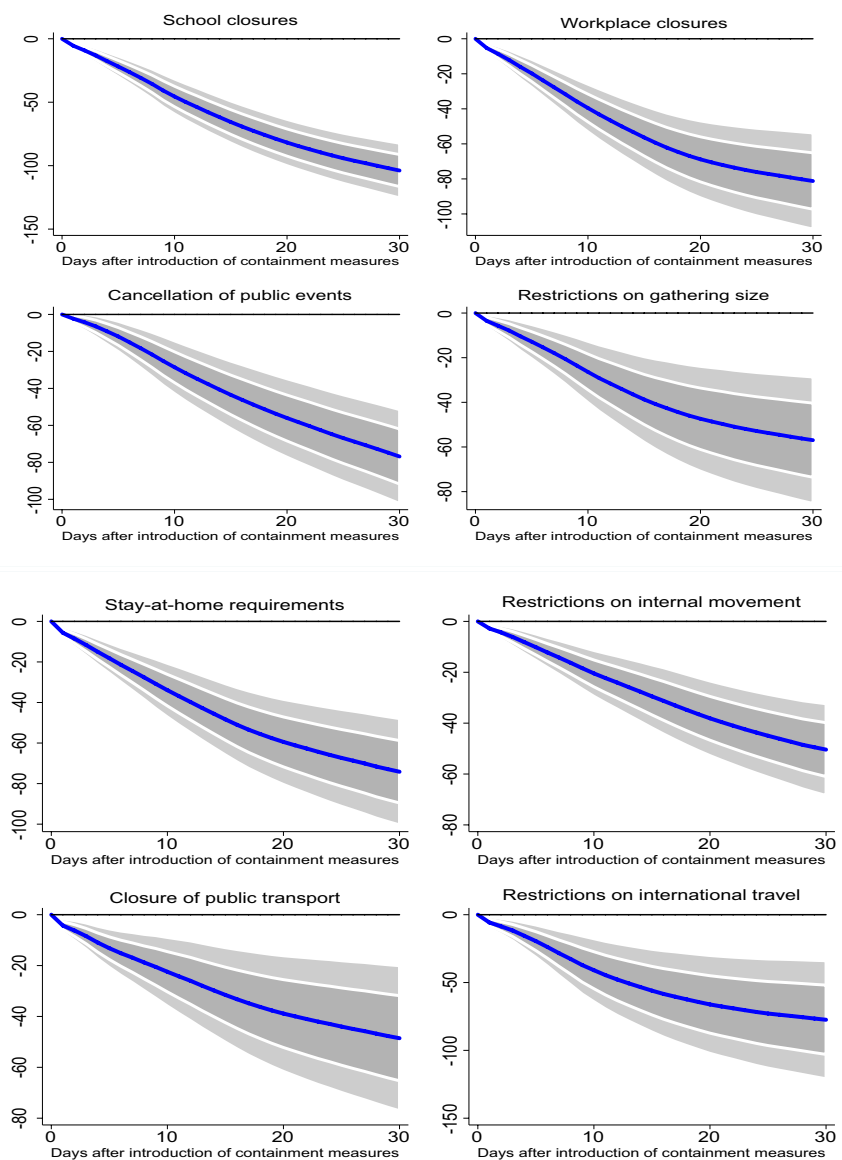

Note: Impulse response functions are estimated using a sample of 50 countries using daily data from the start of the outbreak. The graph shows the response and confidence bands at 90 and 95 percent. The horizontal axis shows the response 30 days after the containment measures. Estimates based on $d_{i, t+h}=u_{i}+\mathrm{q}_{h} c_{i, t}+X_{i, t}^{\prime} \Gamma_{h}+\sum_{\ell=1}^{\mathcal{L}} \psi_{h, \ell} \Delta d_{i, t-\ell}+\varepsilon_{i, t+h}$ and $d_{i, t}$ is the logarithm of COVID-19 infections in country $i$ observed at date $t$. The model is estimated at each horizon $h=0,1, \ldots H$, with a lag structure $\ell=1,2 \ldots \mathcal{L} ; c_{i, t}$ is the index capturing different types containment and mitigation measures, introduced one at a time; $X$ is a matrix of time varying control variables and country specific linear, cubic and quadratic time trends.

Fig. 9 Local projection response of infections to containment measures (one by one)

Looking deeper at the role of fiscal policy measures, the results suggest that both demand-support measures (cash transfers, tax payment deferrals, grants, etc.) and emergency lifelines (loans to households and firms, equity injections, etc.) were effective in mitigating pandemic-induced losses: in countries where demand support measures were of little use, $\mathrm{NO}_{2}$ losses were almost equivalent to a 12 percent decline in industrial production (Fig. 6). On the other hand, governments which deployed considerable demand support measures saw a much smaller decline in industrial production (-7 percent), though not statistically significant. Turning to emergency lifelines, the results suggest that losses in industrial production are 

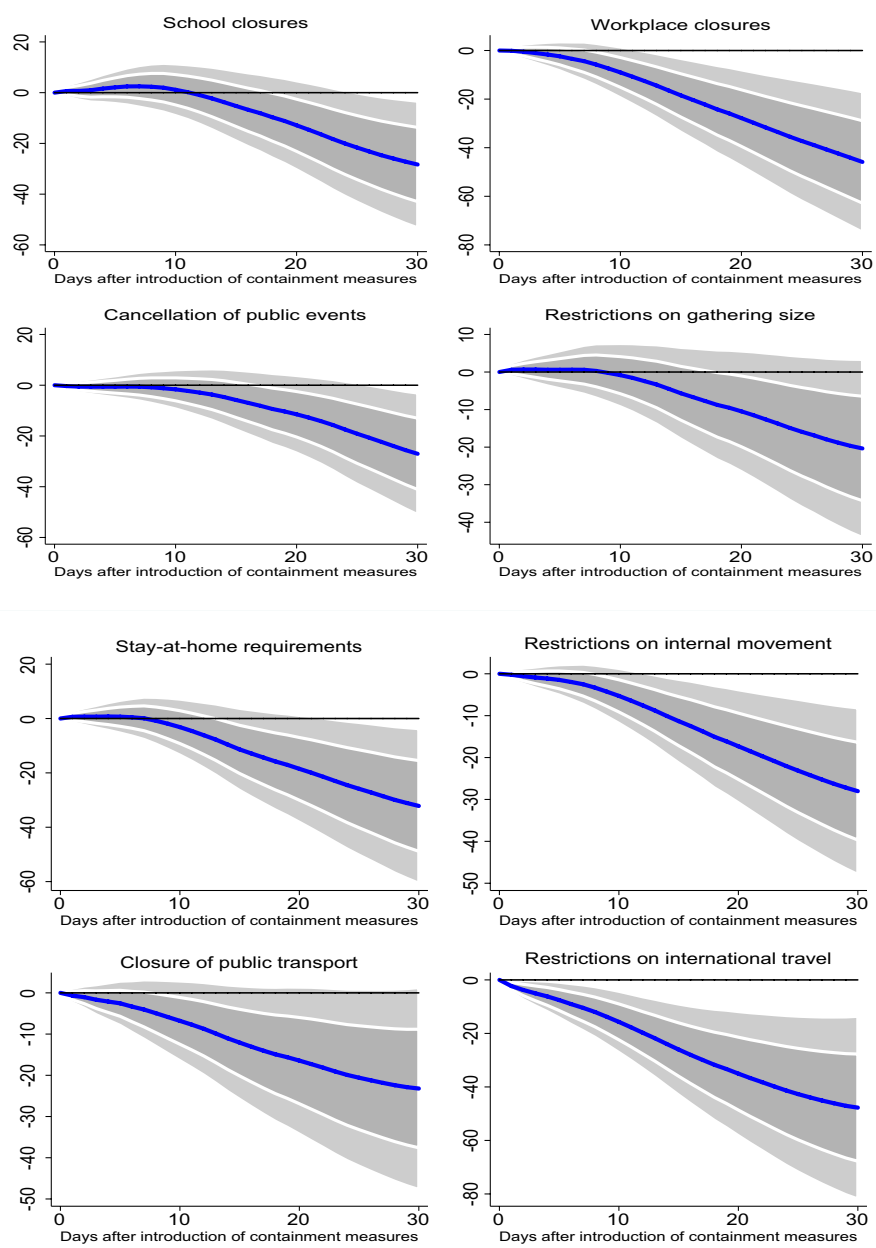

Note: Impulse response functions are estimated using a sample of 50 countries using daily data from the start of the outbreak. The graph shows the response and confidence bands at 90 and 95 percent. The horizontal axis shows the response 30 days after the containment measures. Estimates based on $d_{i, t+h}=u_{i}+\mathrm{q}_{h} c_{i, t}+X_{i, t}^{\prime} \Gamma_{h}+\sum_{\ell=1}^{\mathcal{L}} \psi_{h, \ell} \Delta d_{i, t-\ell}+\varepsilon_{i, t+h}$ and $d_{i, t}$ is the logarithm of COVID-19 fatalities in country $i$ observed at date $t$. The model is estimated at each horizon $h=0,1, \ldots H$, with a lag structure $\ell=$ $1,2 \ldots \mathcal{L} ; c_{i, t}$ is the index capturing different types containment and mitigation measures, introduced one at a time; $X$ is a matrix of time varying control variables and country specific linear, cubic and quadratic time trends.

Fig. 10 Local projection response of fatalities to containment measures (one by one)

starker and more persistent (-15 percent) in countries where lifelines were less used. This is perhaps unsurprising, given that the liquidity measures provided by emergency lifelines assured the continuity of firms and businesses during the lockdown period of the pandemic. On the other hand, in cases where governments' fiscal packages relied heavily on emergency lifelines, losses in industrial production were less pronounced (-12 percent). 
Full sample - January 1, 2020 to September 18, 2020
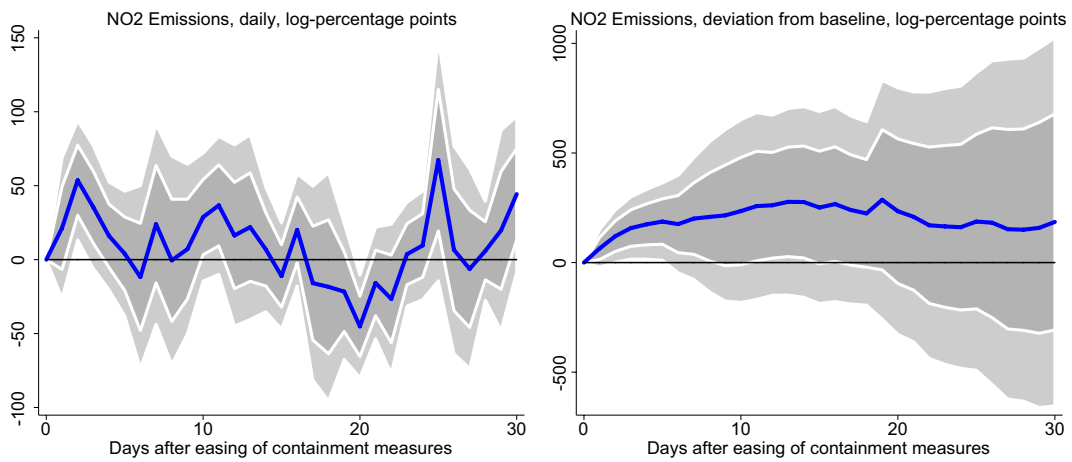

From September 18, 2020 to August 20, 2021
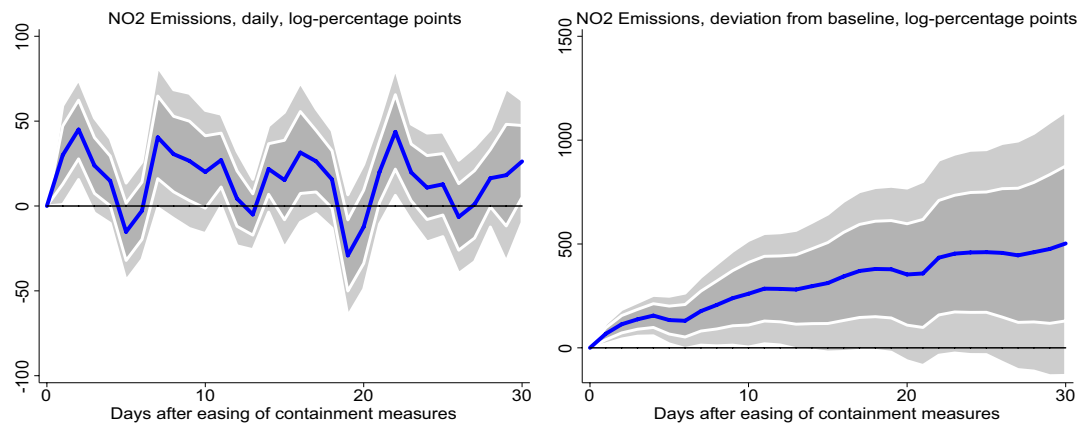

Note: Impulse response functions are estimated using a sample of 45 countries using daily data. The graph shows the response and confidence bands at 90 and 95 percent. The horizontal axis shows the response $\mathrm{x}$ days after the containment measures. Estimates based on $n_{i, t+h}=u_{i}+\sum_{\ell=0}^{\mathcal{L}} \mathrm{q}_{h, \ell} c_{i, t-\ell}+X_{i, t}^{\prime} \Gamma_{h}+\sum_{\ell=1}^{\mathcal{L}} \psi_{h, \ell} \Delta n_{i, t-\ell}+\varepsilon_{i, t+h}$ where $n_{i, t}$ is the logarithm of $\mathrm{NO}_{2}$ emissions in country $i$ observed at date $t$. The model is estimated at each horizon $h=0,1, \ldots H$, with a lag structure $\ell=1,2 \ldots \mathcal{L} ; c_{i, t}$ the index capturing the level of containment and mitigation measures; $X$ is a matrix of time varying control variables and country specific time trends. The regression is estimated using both daily NO2 emissions (left panel) and cumulative emissions (right panel) over period 1 to $h$ to obtain relevant coefficients and standard errors.

Fig. 11 Effect of easing of containment measures

\subsection{Cost-effectiveness of Different Containment Measures}

In this section, we explore how different containment measures compare in terms of economic cost—-through their impact on economic activity and health effectiveness. Our purpose is to examine which types of containment measures resulted in larger short-term tradeoffs between minimizing health risks and economic losses. This can inform the discussion of how countries should re-open their economies as well as how they can respond to a second wave of infections. For this purpose, we analyze the effects on economic activity and infections, of the following containment measures: (i) school closures; (ii) workplace closures; (iii) cancellation of public events; (iv) restrictions on gatherings sizes; (v) closures of public transport; (vi) stay-at-home orders; 


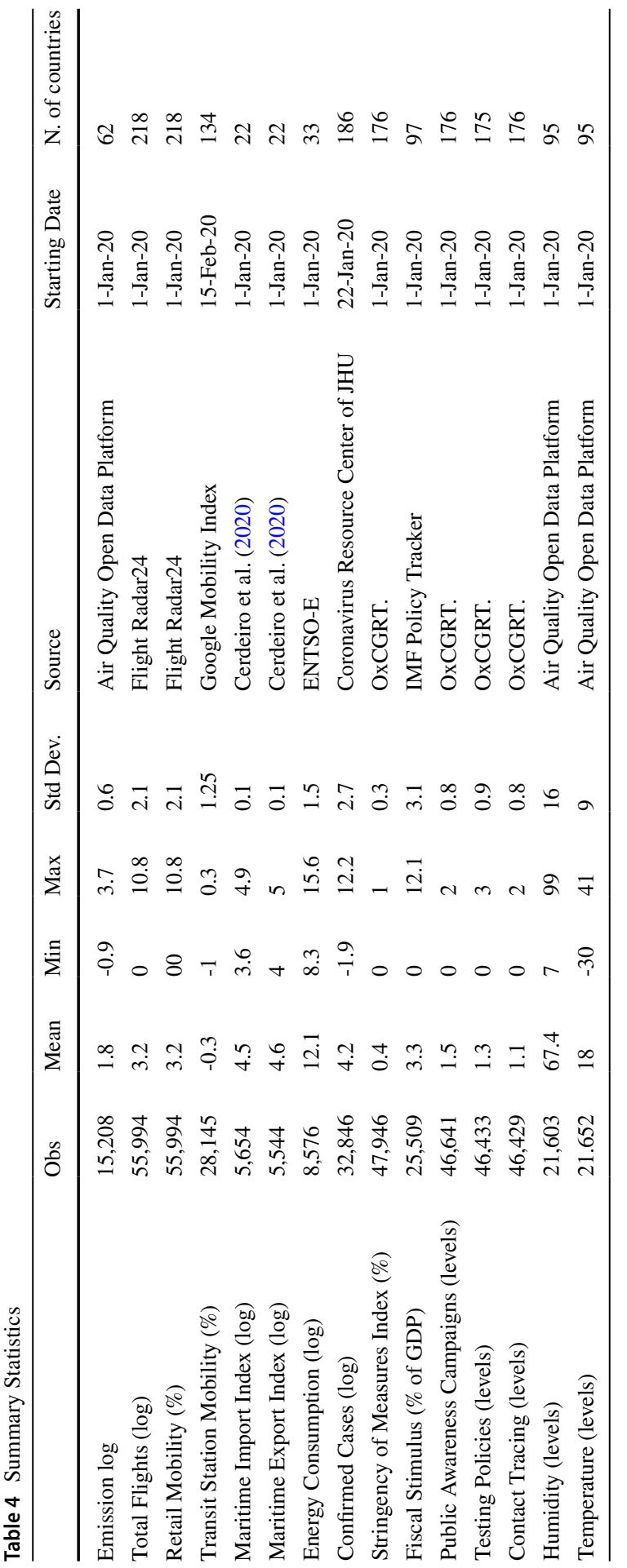



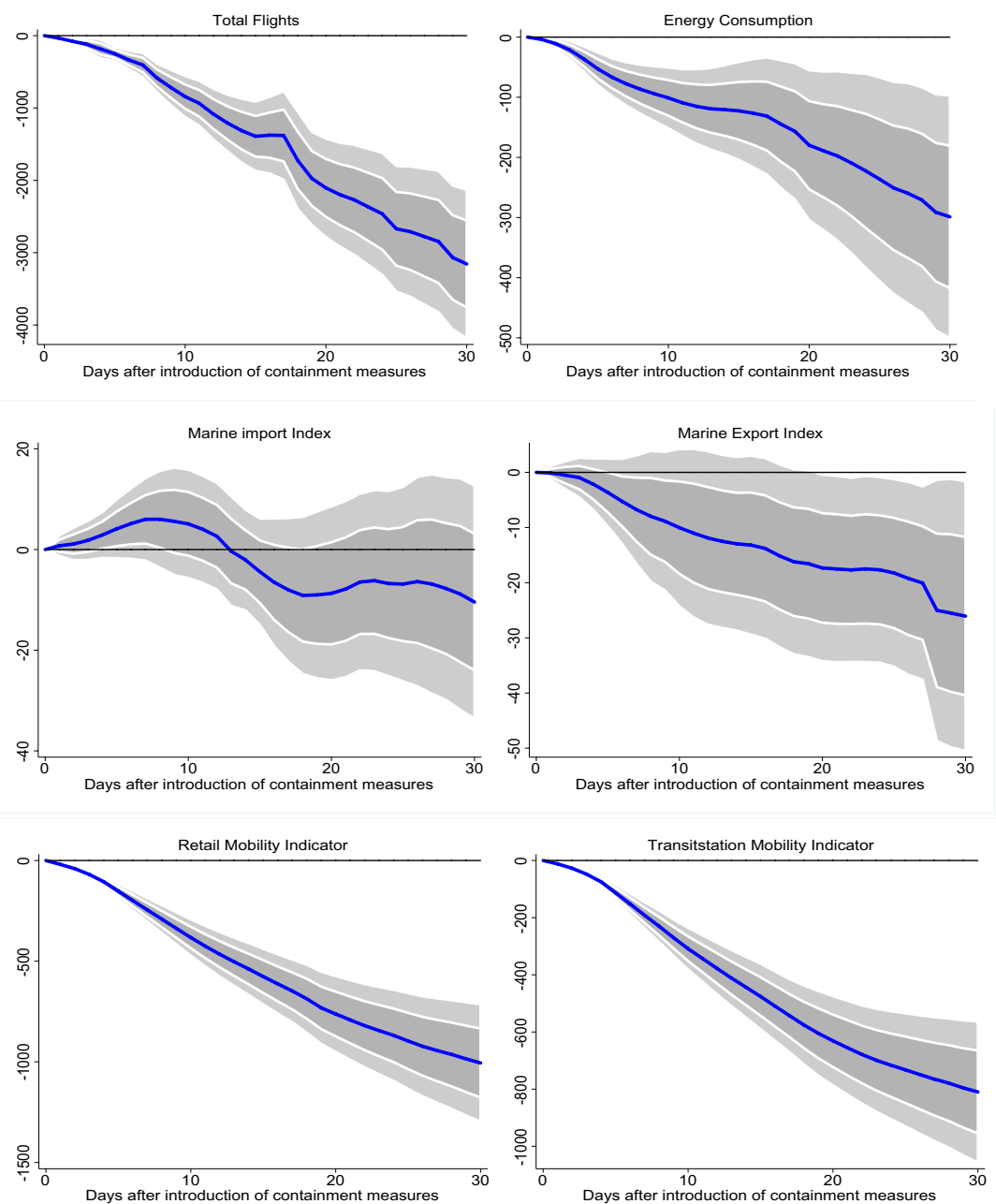

Note: Impulse response functions are estimated using daily data from the start of the outbreak. The graph shows the response and confidence bands at 90 and 95 percent. The horizontal axis shows the response $\mathrm{x}$ days after the containment measures.

Estimates based on $n_{i, t+h}=u_{i}+\sum_{\ell=0}^{\mathcal{L}} \mathrm{q}_{h, \ell} c_{i, t-\ell}+X_{i, t}^{\prime} \Gamma_{h}+\sum_{\ell=1}^{\mathcal{L}} \psi_{h, \ell} \Delta n_{i, t-\ell}+\varepsilon_{i, t+h}$ where $n_{i, t}$ is the logarithm of $\mathrm{NO}_{2}$ emissions in country $i$ observed at date $t$. The model is estimated at each horizon $h=0,1, \ldots H$, with a lag structure $\ell=1,2 \ldots \mathcal{L} ; c_{i, t}$ the index capturing the level of containment and mitigation measures; $X$ is a matrix of time varying control variables and country specific time trends.

Fig. 12 Local projection response of alternative economic indicators

(vii) restrictions on internal movement; and (viii) restrictions on international travel. Moreover, examining the effect of international travel restrictions provides further reassurance on the causal effect of containment measures, given that travel restrictions were mostly implemented in response to outbreaks in other countries and ahead of declining mobility, and are therefore exogenous to domestic conditions. 

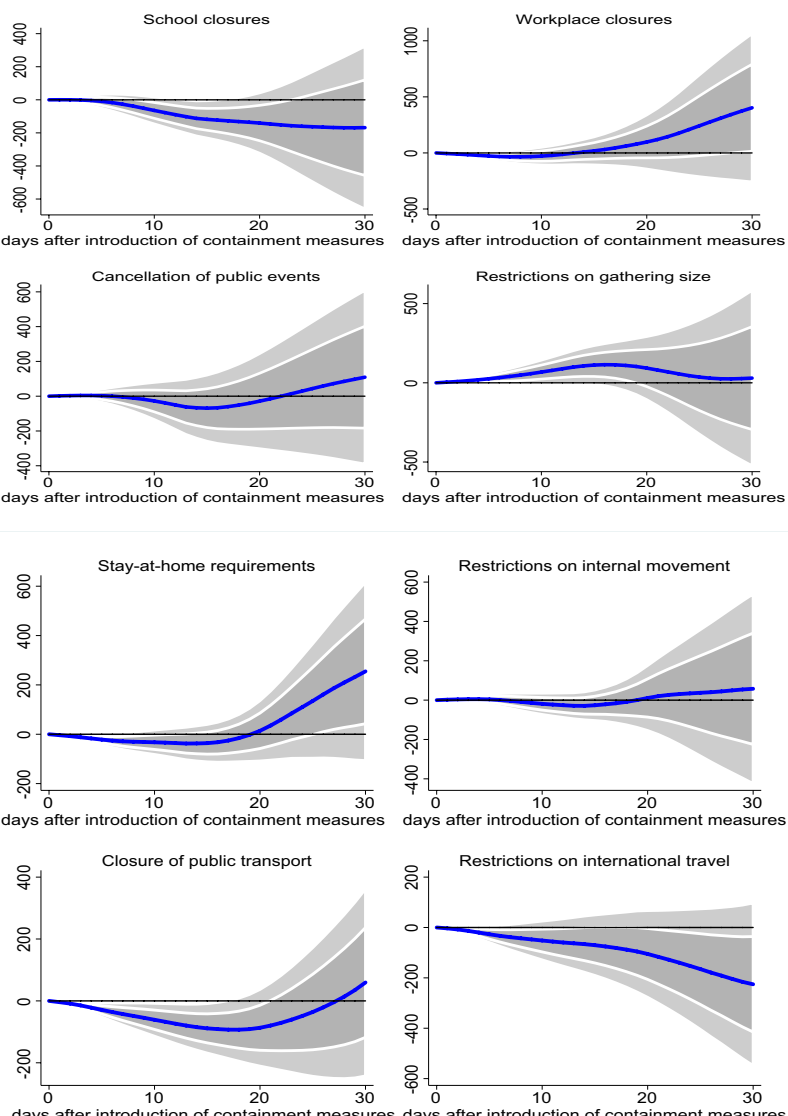

Note: Impulse response functions are estimated using a sample of 50 countries using daily data from the start of the outbreak. The graph shows the response and confidence bands at 90 and 95 percent. The horizontal axis shows the response $\mathrm{x}$ days after the containment measures. Estimates based on $n_{i, t+h}=u_{i}+\mathrm{q}_{h} c_{i, t}+X_{i, t}^{\prime} \Gamma_{h}+\sum_{\ell=1}^{\mathcal{L}} \psi_{h, \ell} \Delta n_{i, t-\ell}+\varepsilon_{i, t+h}$ where $n_{i, t}$ the logarithm of the number of $\mathrm{NO}_{2}$ emissions in country $i$ observed at date $t$. The model is estimated at each horizon $h=0,1, \ldots H$, with a lag structure $\ell=1,2 \ldots \mathcal{L} ; c_{i, t}$ is the index capturing different types containment and mitigation measures, introduced altogether; $X$ is a matrix of time varying control variables and country specific time trends.

Fig. 13 Local projection response of $\mathrm{NO}_{2}$ emissions to containment measures (all together)

To estimate the effects of different containment measures on infections, we follow the approach used by Deb et al. (2020), and adapt Eq. (1) to the following:

$$
d_{i, t+h}=u_{i}+q_{h} c_{i, t}+X_{i, t}^{\prime} \Gamma_{h}+\sum_{\downarrow=1}^{\mathcal{L}} \psi_{h, \uparrow} \Delta d_{i, t-\uparrow}+\varepsilon_{i, t+h}
$$

where $d_{i, t+h}$ and $d_{i, t}$ alternately denotes the logarithm of the number of infections or fatalities, in country $i$ observed at date $t . c_{i, t}$ denotes the OxCGRT Stringency Index. $u_{i}$ are country-fixed effects to account for time-invariant country-specific characteristics (for example, population density, age profile of the population, health capacity, etc.). $X$ is a vector of control variables which includes daily temperature 

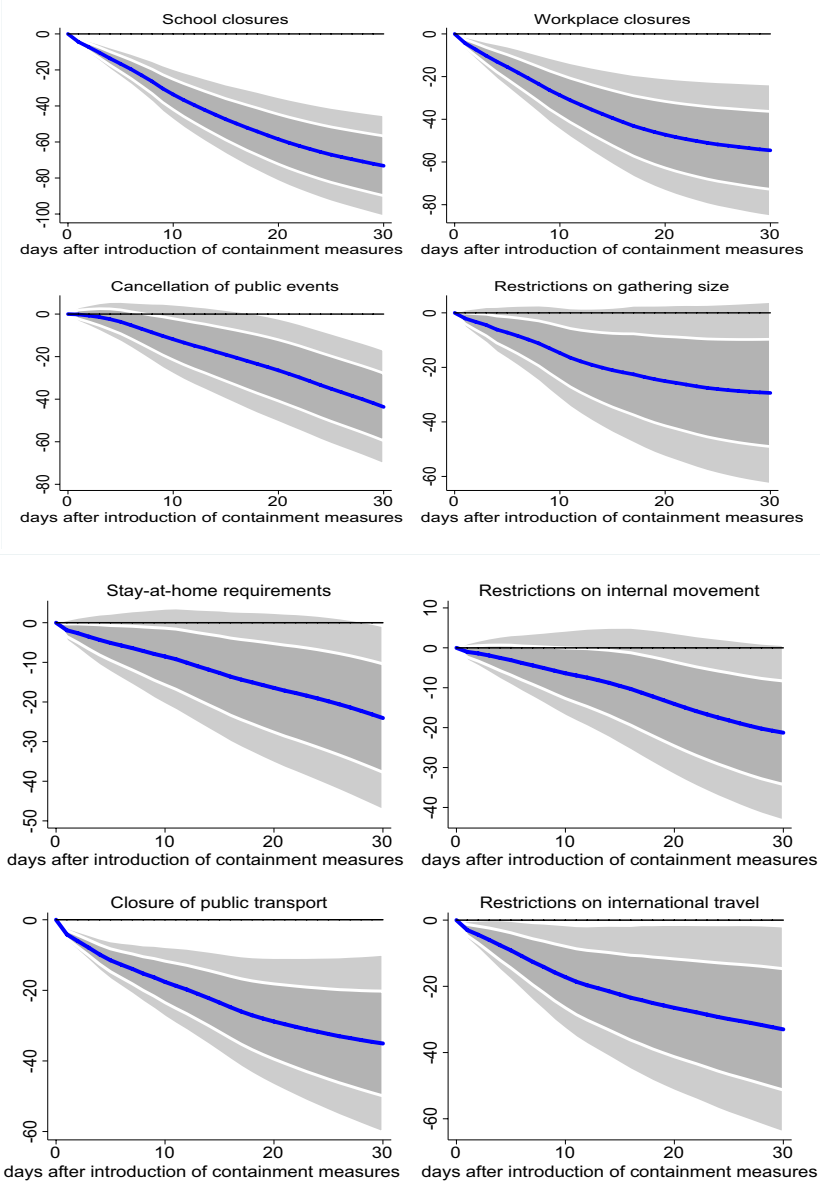

Note: Impulse response functions are estimated using a sample of 50 countries using daily data from the start of the outbreak. The graph shows the response and confidence bands at 90 and 95 percent. The horizontal axis shows the response $\mathrm{x}$ days after the containment measures. Estimates based on $d_{i, t+h}=u_{i}+\mathrm{q}_{h} c_{i, t}+X_{i, t}^{\prime} \Gamma_{h}+\sum_{\ell=1}^{\mathcal{L}} \psi_{h, \ell} \Delta d_{i, t-\ell}+\varepsilon_{i, t+h}$ where $d_{i, t}$ the logarithm of the number of COVID-19 infections in country $i$ observed at date $t$. The model is estimated at each horizon $h=0,1, \ldots H$, with a lag structure $\ell=1,2 \ldots \mathcal{L} ; c_{i, t}$ is the index capturing different types containment and mitigation measures, introduced altogether; $X$ is a matrix of time varying control variables and country specific time trends.

Fig. 14 Local projection response of infections to containment measures (all together)

and humidity levels, NPIs, lagged changes in mobility, and country-specific linear, cubic and quadratic time trends.

Estimating the overall effect of each measure is challenging, because many of the measures were introduced simultaneously. Following Deb et al. (2020), we use two alternative approaches to gauge the potential magnitude of the effect of each of measure. In the first, we introduce each measure one at a time in Eqs. (1) and (3), respectively.

${ }^{9}$ Lags for each measure are not included here as these were typically one-off and not serially correlated. 
Clearly, the problem with this approach is that the estimates suffer from omitted variable bias. In the second approach, we include them all together. While this approach addresses omitted variable bias, the estimates are likely to be less precise due to multicollinearity.

The results for the first approach-the effects of each containment measure on economic activity, infections and fatalities are summarized in Table 3. Figures are reported in Figs. 7, 8, 9, and 10 for the first approach and Figs. 12, 13 and 14 for the second. ${ }^{10}$ They suggest that school closures and cancellation of public events are the most effective measures in curbing infections; but also, they are also associated with lower economic costs. The results also suggest that while workplace closures and international travel restrictions are very effective in curbing infections and fatalities, they are among the costliest measures. Meanwhile, closures of public transport, though costly in economic terms, do not appear to be as effective in curbing infections. Finally, less costly containment measures, such as restrictions on gathering size, are not as successful in lowering COVID19 infections and fatalities compared to other containment measures.

\subsection{Effects of Easing of Containment Measures}

Finally, we assess the impact of the loosening of containment measures on economic activity. Specifically, we look at those countries which began to loosen containment measures towards the end of 2020Q2. Such countries are identified by restricting the data to after the stringency index $c_{i, t}$ has reached its peak value and then was lowered for the remaining time frame. The sample consists of a balanced panel of 45 countries.

Figure 11 shows the estimated dynamic response of the level of $\mathrm{NO}_{2}$ to a unitary decline in the aggregate containment stringency index over the 30-day period following relaxation of the containment measure, together with 90 and 95 percent confidence intervals around the point estimate. The results suggest that relaxing containment measures have led to an increase in $\mathrm{NO}_{2}$ emissions ( 7 percent increase in industrial production), but this increase only equals to about 65 percent of the losses associated with lockdowns. This result may suggest potential scarring from the pandemic as an eventual full reversal of containment measures does not restore economic activity to pre-pandemic levels.

As a robustness check, we also extend the analysis to include data from beyond September 18, 2020 to August 20, 2021 and the results remain robust (Fig. 11, bottom panel).

\section{Conclusions}

Containment measures, though crucial for halting the COVID-19 pandemic, have resulted in large short-term economic losses. In this paper, we provide a first empirical assessment on the impact of COVID-19 containment measures on economic

\footnotetext{
${ }^{10}$ The results for $\mathrm{NO}_{2}$ are less precisely estimated when including all containment measures together. Reassuringly, however, the effects of international travel restrictions-which are exogenous to domestic conditions-remain statistically significant.
} 
activity, through the use of a novel daily database of economic activity indicators, including Nitrogen Dioxide $\left(\mathrm{NO}_{2}\right)$ emissions, international and domestic flights, energy consumption, maritime trade, and mobility indices.

Results suggest that containment measures have had, on average, very large impacts on $\mathrm{NO}_{2}$ emissions, equivalent to a loss of about 10 percent in industrial production over the 30-day period following the implementation of containment measures. Meanwhile, the loosening of containment measures leads to a rebound in economic activity ( 7 percent increase in industrial production), that is smaller in absolute terms than the losses caused by the lockdowns. Results for other economic activity indicators suggest that containment measures have had adverse impacts on flights, energy consumption, maritime trade, and retail and transit mobility.

Fiscal measures used during the COVID-19 crisis played an important role in mitigating the impact of containment measures on economic activity: results suggest that short-term economic losses are greater in countries where less fiscal stimulus was deployed, and specifically where emergency lifeline measures-which typically provided much needed liquidity support to firms, businesses and households during lockdowns-were not used.

Among types of containment measure, school closures and cancellation of public events are the most effective in curbing COVID-19 infections and are less costly in terms of their impact on economic activity. However, other highly effective containment measures, such as workplace closures and restrictions on international travel, are among the costliest measures in economic terms.

\section{Appendix}

\section{Data}

We present here a comprehensive daily database of high-frequency indicators of economic activity.

Flights Flight data are collected from FlightRadar24, which provides real-time information on worldwide flights from several data sources, including automatic dependent surveillance-broadcast (ADS-B), (Multilateration) MLAT and radar data. The database covers international and domestic inbound and outbound flights data for over 200 countries, 84 of which are used in our analysis. Data coverage is on a daily frequency and begins on January 1, 2020. Data for total flights is calculated by summing daily domestic and international flights.

Energy Consumption We use daily data on energy consumption for 33 countries in Europe from ENTSO-E's transparency platform. The platform provides hourly total load of electricity generated per market time unit by plants covered by Transmission System Operators (TSO) and Distribution System Operators (DSO) networks. Coverage in our sample begins from January 1, 2020 and ends on August 1,2020. 
Maritime Imports and Exports Indices For maritime import and export indices, we use data from Cerdeiro et al. (2020), who build real-time indicators of world seaborne trade using raw Automatic Identification System (AIS) signals emitted by global vessel fleets through their transponders. They use machine-learning techniques to transform AIS data, which contain information on vessels' speed, location, draught, etc., into import and export maritime indices. Their database produces import and export indices for 22 countries. Data coverage begins on January 1, 2020.

\section{Impact of Containment Measures on Other Indicators of Economic Activity}

We also examine whether containment measures have had an impact on other indicators of economic activity, namely: (i) flights; (ii) energy consumption; (iii) maritime import and export indices; and (iv) retail and transit mobility indices. These variables can shed light on the effect of containment measures on different sectors of the economy, such as tourism, trade, and retail consumption.

Results for Eq. (1) for each indicator are reported in Fig. 12. They suggest that the impact of containment measures has been overwhelmingly adverse across all sectors, and most importantly tourism. Specifically, the results indicate that containment measures have reduced the total number international and domestic flights by more than 99 percent in the 30-day period following the implementation of containment measures. Total energy consumed has declined by more than 95 percent; maritime imports and exports have been reduced by around 30 percent, though the impact is more pronounced and significant on exports; retail and transit mobility have been reduced by more than 400 percentage points relative to country-specific paths in the absence of intervention.

\section{References}

Acemoglu D, Chernozhukov V, Werning I, Whinston M (2020) Optimal Targeted Lockdowns in a MultiGroup SIR Model, NBER Working Papers, 27102

Alesina AF, Furceri D, Ostry JD, Papageorgiou C Quinn DP (2019) Structural Reforms and Elections: Evidence from a World-Wide New Dataset (No. w26720). National Bureau of Economic Research

Alvarez F, Argente D, Lippi F (2020) "A Simple Planning Problem for COVID-19 Lockdown," NBER Working Papers, 26981

Aspri A, Elena B, Alberto G, Etienne W (2021) Mortality containment vs. economics opening: Optimal policies in a SEIARD model. J Math Econ 93:102490

Atolia M, Papageorgiou C Turnovsky SJ (2021) Re-opening after the lockdown: Long-run aggregate and distributional consequsences of COVID-19. J Math Econ 93:102481

Auerbach AJ, Gorodnichenko Y (2013) Output Spillovers from Fiscal Policy. Am Econ Rev 103(3):141-146

Barro RJ, Ursua JF, Weng J (2020) The coronavirus and the great influenza pandemic: Lessons from the "spanish flu" for the coronavirus's potential effects on mortality and economic activity. NBER Working Paper No. 26866

Caulkins Jonathan P., Dieter G, Feichtinger G, Hartl RF, Kort PM, Prskawetz A, Seidl A, Wrzaczek S (2021) The optimal lockdown intensity for COVID-19. J Math Econ 93:102489

Cerdeiro D, Komaromi A, Lui Y Saeed M (2020) World Seaborne Trade in Real Time: A Proof of Concept for Building AIS-based Nowcasts from Scratch. IMF Working Paper, Forthcoming 
Chen S, Igan D, Pierri N, Presbitero A (2020) "Tracking the Economic Impact of COVID-19 and Mitigation Policies in Europe and the United States," IMF Working Paper, 20/125

Chinazzi et al (2020) The effect of travel restrictions on the spread of the 2019 novel coronavirus (COVID-19) outbreak. Science 368:395-400

Deb P, Furceri D, Ostry J, Tawk N (2020) The Effects of Containment Measures on the COVID-19 Pandemic. Covid Economics: Vetted and Real-Time Papers 2020(19):53-86

Eichenbaum M, Rebelo S, Trabandt M (2020) The Macroeconomics of Epidemics. NBER Working Papers 26882, National Bureau of Economic Research, Inc

Granger CWJ, Teräsvirta T (1993) Modelling Nonlinear Economic Relationships Oxford University Press New York

Gupta S, Montenovo L, Thuy D, Felipe Lozano Rojas N, Schmutte IM, Simon KI, Weinberg BA, Wing C (2020) Effects of Social Distancing Policy on Labor Market Ouctomes. NBER Working Paper No. 27280 May 2020

Henderson JV, Storeygard A, Weil DN (2012) Measuring economic growth from outer space. American Economic Review 102(2):994-1028

Henderson V, Storeygard A, Weil DN (2011) A bright idea for measuring economic growth. American Economic Review 101(3):194-199

Hsiang S et al (2020) The effect of large-scale anti-contagion policies on the Covid-19 pandemic. Nature. https://doi.org/10.1038/s41586-020-2404-8

Jinjarak Y, Ahmed R, Nair-Desai S, Xin W, Aizenman J (2020) Accounting for global COVID-19 diffusion patterns, January-April 2020. Economics of Disasters and Climate Change 4(3):515-559

Jordà Ò (2005) Estimation and Inference of Impulse Responses by Local Projections. American Economic Review 95(1):161-182

Kermack WO, McKendrick AG (1927) A contribution to the mathematical theory of epidemics. Proc R Soc Lond A115700-721

Kraemer et al (2020) The effect of human mobility and control measures on the COVID-19 epidemic in China. Science 368:493-497

Kumar S, Muhuri P (2019) A novel GDP prediction technique based on transfer learning using CO2 emission dataset. Appl Energy 253:113476

Lin JT, McElroy MB (2011) Detection from space of a reduction in anthropogenic emissions of oitrogen Oxides during the Chinese economic downturn. Atmospheric Chem Phys

Ma C, Rogers J, Zhou S (2020) Modern Pandemics: Recession and Recovery. Working paper

Maloney W, Taksin T (2020) Determinants of social distancing and economic activity during COVID-19: A global view. Covid Economics: Vetted and Real-Time Papers 2020(13):157-177

Ramey VA, Zubairy S (2018) Government spending multipliers in good times and in bad: evidence from US historical data. J Polit Econ 126(2):850-901

Teulings CN, Zubanov N (2014) Is Economic Recovery a Myth? Robust Estimates of Impulse Responses. J Appl Economet 29:497-514

Tian $\mathrm{H}$ et al (2020) An investigation of transmission control measures during the first 50 days of the COVID-19 epidemic in China. Science. https://doi.org/10.1126/science.abb6105(2020)

Publisher's Note Springer Nature remains neutral with regard to jurisdictional claims in published maps and institutional affiliations. 